\title{
Mosquitoes of eastern Amazonian Ecuador: biodiversity, bionomics and barcodes
}

\author{
Yvonne-Marie Linton ${ }^{1,2}+{ }^{+}$, James E Pecor ${ }^{1,2}$, Charles H Porter ${ }^{3}$, Luke Brett Mitchell2, \\ Andrés Garzón-Moreno², Desmond H Foley, ${ }^{1,2}$ David Brooks Pecor ${ }^{1,2}$, Richard C Wilkerson ${ }^{1,4}$
}

'Walter Reed Army Institute of Research, Entomology Branch, Silver Spring, MD, USA ${ }^{2}$ Walter Reed Biosystematics Unit, Museum Support Center, Smithsonian Institution, Suitland, MD, USA ${ }^{3}$ Centers for Disease Control and Prevention, Atlanta, GA, USA ${ }^{4}$ Department of Entomology, Smithsonian Institution, Washington DC, USA

Two snapshot surveys to establish the diversity and ecological preferences of mosquitoes (Diptera: Culicidae) in the terra firme primary rain forest surrounding the Tiputini Biodiversity Station in the UNESCO Yasuni Biosphere Reserve of eastern Amazonian Ecuador were carried out in November 1998 and May 1999. The mosquito fauna of this region is poorly known; the focus of this study was to obtain high quality link-reared specimens that could be used to unequivocally confirm species level diversity through integrated systematic study of all life stages and DNA sequences. A total of 2,284 specimens were preserved; 1,671 specimens were link-reared with associated immature exuviae, all but 108 of which are slide mounted. This study identified 68 unique taxa belonging to 17 genera and 27 subgenera. Of these, 12 are new to science and 37 comprise new country records. DNA barcodes [658-bp of the mtD$N A$ cytochrome c oxidase (COI) I gene] are presented for 58 individuals representing 20 species and nine genera. DNA barcoding proved useful in uncovering and confirming new species and we advocate an integrated systematics approach to biodiversity studies in future. Associated bionomics of all species collected are discussed. An updated systematic checklist of the mosquitoes of Ecuador $(n=179)$ is presented for the first time in 60 years.

Key words: Ecuador - Amazon - Culicidae - DNA barcodes - species list - habitat

The Yasuní Biosphere Reserve and National Park cover an area of $9,823 \mathrm{~km}^{2}$ between the Napo and Curaray rivers in the Napo, Pastaza and Orellano provinces of northeastern Ecuador $\left(00^{\circ} 10^{\prime} 01^{\circ} 45^{\prime} \mathrm{S}, 75^{\circ} 20^{\prime} 77^{\circ} 00^{\prime} \mathrm{W}\right)$. The reserve comprises the largest remaining pristine tropical forest in eastern Ecuador and is characterised by low plains alternating with the foothills of the Andes Mountain Range. The area has long been recognised internationally as a biodiversity hotspot and was designated UNESCO Biosphere status in 1989 at the request of the Ecuadorian government. Plant diversity is extremely high and it is one of only nine places worldwide known to support over 4,000 vascular plant species per $10,000 \mathrm{~km}^{2}$. A single hectare is reported to support more than 100,000 species of insect. More than 204 species of mammals, including 13 primates, 550 birds and 382 fish (including 43 endemic vertebrates) have been reported from the Park (Bass et al. 2010) (wcsecuador.org).

Not only is Yasuní National Park arguably one of the World's most significant biodiversity hotspots, it is also home to a wealth of human cultural diversity, including the Tagaeri and Taromenane peoples, as well as some of

doi: 10.1590/0074-0276130440

Financial support: WRAIR and the Smithsonian Institution, National Research Council Senior Associateship Award (to YML), fieldwork supported by University of South Carolina (to RCW) The paper reflects the views of the authors and not that of the US army. + Corresponding author: linton.yvonne3@gmail.com

Received 10 September 2013

Accepted 2 December 2013 the last remaining uncontacted tribes. Unfortunately, as well as richness in human, plant and animal biodiversity, Yasuní is under serious threat due to its plentiful oil reserves and the accompanying impacts that oil extraction, human disturbance and associated activities bring (e.g. deforestation, illegal logging and hunting, reduction in large mammal numbers) (Zapata-Ríos et al. 2006).

In 1995, the Tiputini Biological Station (TBS) was established by the Universidad San Francisco de Quito in collaboration with Boston University, to facilitate research and understanding of forest ecosystem management within the Yasuní Biosphere Reserve and National Park. TBS is situated in a 650 -hectare $(1,500$-acre) tract of primary lowland rainforest to the south of the Park and encompasses a variety of habitats, ranging from upland forests, seasonally flooded lowland forest, palm swamps, small oxbow lakes and streams and other wetlands. The main forest type surrounding the station is terra firme (Oxford et al. 2012).

The mosquito faunal list for Ecuador was last revised by Leví-Castillo (1953) and there is no updated species list, nor current regional taxonomic keys available, making species verifications laborious. Very little information is known on the species diversity or ecological parameters of the Culicidae of the Ecuadorian Amazon (Leví-Castillo 1953, Heinemann \& Belkin 1979). This study focuses on documenting the sylvan mosquito diversity and ecological parameters for species collected in the forest environs surrounding the TBS, through collections of immature stages and adult mosquitoes in November 1998 and May-June 1999.

Mosquitoes were collected in forest environments, mainly as immatures. Specimens were link-reared fol- 
lowing the procedures advocated by Belkin et al. (1965) providing high quality associated males and females with larval and/or pupal skins for rigorous taxonomic verification and integrated systematics study. DNA barcodes, 658-bp fragments of the mtDNA cytochrome c oxidase (COI) gene, were generated for some specimens to aid identification. Exact distribution coordinates and details on bionomics for all species collected are given. Species recorded herein were combined with other published documents and reports and an updated checklist for the 179 Culicid species known from Ecuador is presented for the first time in 60 years.

\section{MATERIALS AND METHODS}

Specimen collection - Mosquito collections were carried out in a range of natural and artificial habitats in the forest environment within a $10 \mathrm{~km}$ circumference of the TBS, Yasuní Biosphere Reserve and National Park, Orellana province, Ecuador (Fig. S1).

Collections $(n=121)$ of immature mosquitoes were carried out in aquatic habitats within the forest, including permanent standing water bodies (e.g., stream margins, lakes), temporary water bodies (e.g., ground pools, tree holes) and container habitats (e.g., rainwater collections in bromeliad and Heliconia axils as well as artificial containers and oviposition traps). Each discreet habitat was registered as a separate collection and detailed notes on habitat and locality information noted on a standardised collection form, which can be downloaded from the Walter Reed Biosystematics Unit (WRBU) website (wrbu.si.edu/Techniques.html). Where gaps in the forest canopy permitted, GPS readings were taken. Otherwise, detailed notes on each locality were documented in relation to positions along the TBS trails, allowing retrospective georeferencing using Google Earth. All coordinates were converted to decimal degrees (Foley et al. 2009) and distributions records are freely available in MosquitoMap (mosquitomap.org).

Depending on habitat, immature mosquitoes were collected using either a standard larval dipper (BioQuip, CA, USA) or a turkey baster and carefully transferred to a WhirlPak ${ }^{\circledR}$ plastic bag, using wide-mouth glass pipettes for transport to the laboratory. Specimens were individually link-reared to adults, following the modified procedures of Belkin et al. (1965) summarised in Gaffigan and Pecor (1997), ensuring a good series of high-quality morphological voucher adult specimens (of both sexes) with associated larval and/or pupal skins upon which to undertake the morphological assessment. Adults were mounted on paper points attached to stainless steel insect pins. The associated immature exuviae were preserved in $80 \%$ ethanol and subsequently mounted on microscope slides. A subset of male genitalia were clipped and mounted on microscope slides for further taxonomic verification. In addition to morphological vouchers, some whole larvae and reared adult specimens (particularly males) of perceived morphotaxa were preserved in $100 \%$ ethanol for later DNA analysis.

Human landing catches were not carried out in this study, but a few individuals found landing on the collectors whilst up the tower in the canopy were collected us- ing manual aspirators and later pinned (EC126, EC168). In addition, three Shannon Traps (EC124, EC139, EC259), one indoor resting (EC219) and one outdoor resting (EC127) collection yielded adults (Fig. S1, Supplementary data 1). In some cases, identification was impossible due to poor quality (rubbed) specimens and lack of differentiating characters in the adult female life stage. Only those adults identified with certainty are reported to species herein; all others are identified to subgenera.

Morphological identification - There is no single morphological key to facilitate the identification of all known mosquitoes of Ecuador. The multi-entry webbased keys developed by the WRBU for South America (wrbu.si.edu/southcom MQkeys.html) were used to determine generic level identifications and species level identification for some better-known taxa. These multientry keys facilitate identification of damaged specimens by the ability to skip questions directed at missing or damaged body parts. In addition, available dichotomous keys and original species descriptions of all life stages and the male genitalia were compiled through literature freely available on the WRBU website (wrbu.org).

Important references used for species identifications by taxonomic groups included: Tribe Aedini (Berlin 1969, Schick 1970, Zavortink 1972, Arnell 1973), Anopheles (Cova-Garcia 1961, Zavortink 1973, Faran 1980, Faran \& Linthicum 1981, Wilkerson \& Sallum 1999, González \& Carrejo 2007), Chagasia (Harbach \& Howard 2009), Culex (Rozeboom \& Komp 1950, Bram 1967, Valencia 1973, Berlin \& Belkin 1980, Pecor et al. 1992, Sallum \& Forattini 1996), Haemagogus (Zavortink 1972, Arnell 1973), Onirion (Harbach \& Peyton 2000), Psorophora (Guedes \& Souza 1964), Sabethes (Harbach 1991, Hall et al. 1999), Trichoprosopon (Stone 1944, Zavortink 1979a, b) and Wyeomyia (Judd 1998). Lane (1953) was used as a general reference. Authors associated with species names, along with standardised generic and subgeneric abbreviations, are given in the final Ecuador species list (Supplementary data 2).

Molecular identification - DNA from single legs plucked from pinned adults or whole ethanol-preserved larva or adults were extracted using the QIAgen ${ }^{\circledR}$ DNeasy Blood \& Tissue Kit on the BioSprint 96 automated DNA extraction platform (QIAgen ${ }^{\circledR}$, Germantown, MD, USA). A 710-bp amplicon (658-bp less primers) corresponding to the universal "barcoding" region of the mitochondrial COI I gene was amplified using the LCO1490 \& HCO2198 primers of Folmer et al. (1994), using the standard protocol of the Mosquito Barcoding Initiative (headed by Y-ML and RCW). Each PCR contained $1 \mu \mathrm{L}$ of DNA template, $1 \times \mathrm{NH}_{4}$ buffer, $0.5 \mathrm{mM}$ of each deoxynucleotide triphosphate, $2 \mathrm{mM} \mathrm{MgCl}, 0.3 \mu \mathrm{M}$ each primer, $0.2 \mathrm{U}$ of Taq polymerase (BioLine, Taunton, MA, USA), made up to a total volume of $10 \mu \mathrm{L}$ using $\mathrm{ddH}_{2} 0$. The polymerase chain reaction (PCR) cycle was: $95^{\circ} \mathrm{C}$ for $5 \mathrm{~min}, 35$ cycles of $95^{\circ} \mathrm{C}$ for $30 \mathrm{~s}, 48^{\circ} \mathrm{C}$ for $30 \mathrm{~min}$ and $72^{\circ} \mathrm{C}$ for $30 \mathrm{~s}, 72^{\circ} \mathrm{C}$ for $5 \mathrm{~min}$ and a $10^{\circ} \mathrm{C}$ hold.

Two microlitres of the PCR product was removed and mixed with $2 \mu \mathrm{L}$ of $5 \mathrm{x}$ loading dye before loading into wells in a $1.5 \%$ agarose gel containing $0.5 \mathrm{mg} / \mathrm{mL}$ 
of ethidium bromide. Gels were run at $100 \mathrm{~V}$ for $8 \mathrm{~min}$, prior to ultraviolet visualisation. PCR products were cleaned by adding $2 \mu \mathrm{L}$ of ExoSAP-IT ${ }^{\circledR}$ (USB Co, Cleveland, $\mathrm{OH}, \mathrm{USA}$ ), diluted $1: 4$ with $\mathrm{ddH}_{2} 0$, to the remaining $8 \mu \mathrm{L}$ of positive PCR products. Samples were put back into the thermocycler and run at $37^{\circ} \mathrm{C}$ for $30 \mathrm{~min}$, followed by $80^{\circ} \mathrm{C}$ for $20 \mathrm{~min}$.

Bi-directional sequencing was carried out on an ABI 3730 automated sequencer (PE Applied BioSystems ${ }^{\mathrm{TM}}$, Warrington, England) using the original PCR primers and the Big Dye Terminator Kit ${ }^{\circledR}$ (PE Applied BioSystems ${ }^{\mathrm{TM}}$ ). Sequences were edited in Sequencher ${ }^{\mathrm{TM}}$ v.4.8 (Genes Codes Co, Ann Arbor, MI, USA). Similarities with publicly available sequences were assessed using Basic Local Alignment Search Tool (blast.ncbi.nlm.nih. gov/Blast.cgi). Comparisons with unpublished barcode records were checked through the Identification System of the Barcode of Life Database (BOLD) (barcodinglife. org/index.php/IDS_OpenIdEngine). COI sequences generated contribute to the larger dataset of the Mosquito Barcoding Initiative. Intra and interspecific variation was calculated using Kimura two-parameter distance algorithm (Kimura 1980) in MEGA v.5.2.2 (Tamura et al. 2011). Distance calculations involved all 658 bp of the barcode fragment. Sixty variable nucleotide sequences were detected in the 21 species dataset and all nucleotides were included in pairwise comparisons.

Voucher specimens - Details of voucher specimens stored in the Culicid and frozen collections of the Smithsonian Institution, National Museum of Natural History (NMNH), including associated exuviae, genitalia preps and DNA, are explicitly listed by species in Supplementary data 3. Full collection site details, including georeferences and species determined by collection site are listed in Supplementary data 1. Collection numbers run sequentially, but EC101-102, EC109, EC119, EC129, EC182, EC185, EC190-192, EC211, EC260-261 and EC265 yielded no specimens and are omitted. Collections EC220-EC253 are also excluded as they occurred outside the study area.

Fully digitised specimen level data records and the original collection sheets are held in the WRBU accession ACC1682 and are incorporated into the MosquitoMap section of VectorMap (vectormap.org) (headed by DHF). A schematic map of the trails surrounding TBS is available from Y-ML on request. Details of specimens used for DNA, along with COI barcode sequences and the original chromatograms can be accessed through the BOLD (boldsystems.org) under the project Mosquitoes of the Ecuadorian Amazon. DNA sequences are available in GenBank (ncbi.nlm.nih.gov/genbank) under accessions KF670990-KF671024 and KF671027-KF671044. The DNA barcode sequences of some Anopheles (Ker.) lepidotus from this collection were published previously (Harrison et al. 2012) (JQ041282-JQ041286).

\section{RESULTS AND DISCUSSION}

Mosquito collections were carried out in the forest environs around the TBS between 29 October-13 November 1998 (WRBU ACC1682; collections EC100-EC219) and 25 May-2 June 1999 (WRBU ACC1682; collections
EC254-EC270). These focussed primarily on collections of immatures for link-rearing, but also included a few adult collections (Shannon trap, incidental human landing, indoor resting and outdoor resting). A total of 2,284 voucher specimens are preserved and these are housed in the mosquito collections of the Smithsonian Institution, NMNH. Of these, 1,671 specimens have associated immature exuviae, all but 108 of which are slide mounted. To further verify species identifications, the male genitalia of 121 individuals were softened overnight, then clipped, cleared and permanently mounted on slides. Slide-mounted exuviae and male genitalia preps are labelled with the same unique specimen numbers as their associated adults. Full details of associated life stages (including GenBank accessions for sequenced specimens) are listed in Supplementary data 3.

Biodiversity survey (morphology and DNA barcodes) - This study identified 68 unique taxa belonging to 17 genera and 27 subgenera as follow: Anopheles (An.) [subgenera Anopheles (Ano.), Kerteszia (Ker.), Lophopodomyia (Lph.), Nyssorhynchus (Nys.), Stethomyia (Ste.)], Chagasia (Ch.), Culex (Cx.) [subgenera Anoedioporpa (And.), Carrollia (Car.), Culex (Cux.), Melanoconion (Mel.), Microculex (Mcx.)], Haemagogus (Hg.) [subgenus Haemagogus (Hag.)], Limatus (Li.), Lutzia (Lt.) [subgenus Lutzia (Lut.)], Ochlerotatus (Oc.) [subgenera Chrysoconops (Chs.), Protoculex (Pcx.), Protomacleaya (Pro.)], Onirion (On.), Orthopodomyia (Or.), Psorophora (Ps.) [subgenera Grabhamia (Gra.), Janthinosoma (Jan.)], Runchomyia (Ru.) [subgenus Ctenogoeldia (Cte.)], Sabethes (Sa.) [subgenera Peytonulus (Pey.), Sabethes (Sab.)], Toxorhynchites (Tx.) [subgenus Lynchiella (Lyn.)], Trichoprosopon (Tr.), Uranotaenia (Ur.) [subgenus Uranotaenia (Ura.)] and Wyeomyia (Wy.) [subgenera Decamyia (Dec.), Dodecamyia (Dod.), Hystatomyia (Hys.), Miamyia (Mia.), Wyeomyia (Wyo.)]. A quantitative list of all confirmed species are given (Fig. S1, Supplementary data 3) along with information on bionomics and collection localities (Fig. S1, Supplementary data 1).

In conjunction with morphological analysis of available life stages, DNA barcodes were generated for 58 questionable specimens and used to determine their specific identity. COI sequences were compared with topotypic and/or expertly identified specimens in the databank of the Mosquito Barcoding Initiative and those available in GenBank. Comparison of these 58 sequences allowed the verification of 20 species in nine genera, including five of the new species discovered: An. (Ano.) sp. nr. fluminensis, An. (Nys.) sp. nr. konderi, Ch. sp. nr. fajardoi, Cx. (And.) sp. nr. conservator, Wy. (Dod.) sp. nr. aphobema, as well as the confirmation of An. (Ste.) sp. undet. (Figure, Supplementary data 3).

Somewhat incredibly, 37 of the 68 species confirmed here from Yasuní National Park comprise new country records for Ecuador. These include 12 species new to science and one further undetermined species in Anopheles (Stethomyia), a subgenus not previously reported from Ecuador (Supplementary data 2). More than half of all specimens collected (53.3\%) comprised the following five species: $W y$. (Dec.) ulocoma $(\mathrm{n}=462), T r$. digitatum ( $\mathrm{n}=279), C x$. (Cux.) mollis $(\mathrm{n}=181)$, An. (Nys.) sp. $\mathrm{nr}$. 


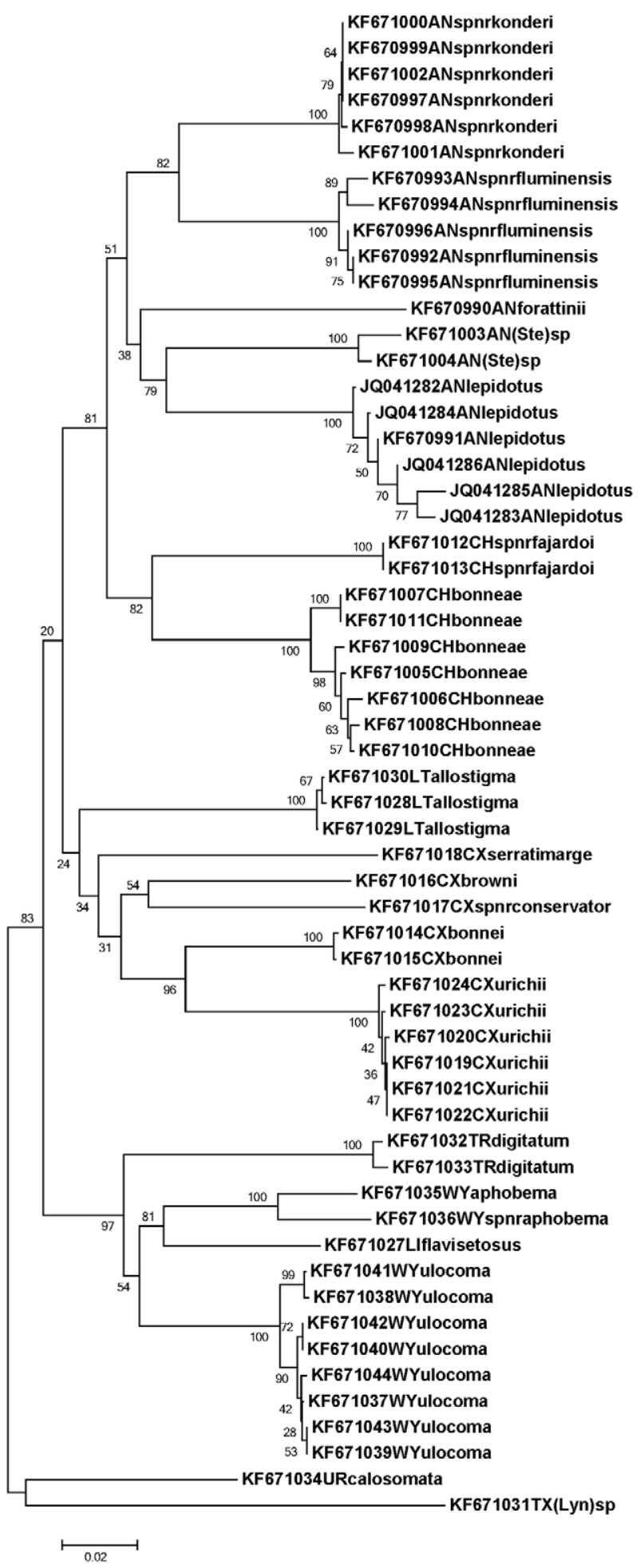

Figure: bootstrap consensus tree of cytochrome c oxidase sequences $(n=58)$ inferred using the neighbour-joining method of Saitou and Nei (1987). The bootstrap consensus tree was inferred from 5,000 replicates (Felsenstein 1985). Branches corresponding to partitions reproduced in less than $50 \%$ of replicates are collapsed. Percentage of replicate trees in which the associated taxa clustered together in the bootstrap test is shown next to the branches. Evolutionary distances were calculated using Kimura two-parameter distance algorithm (Kimura 1980). Scale bar represents sequence (\%) divergence between samples. The final dataset comprised 658 nucleotides, including all codon positions. Analysis was carried out in MEGA5 (Tamura et al. 2011). 
konderi $(\mathrm{n}=154)$ and $C x$. (Car.) urichii $(\mathrm{n}=141)$ (Fig. S1, Supplementary data 3). Species identified are listed by taxonomic groupings below.

Subfamily Anophelinae - Anopheles: Eight species of Anopheles were collected, representing five subgenera: Anopheles, Kerteszia, Lophopodomyia, Nyssorhynchus and Stethomyia. Integrated morphological and molecular study identified the following taxa: $A n$. (Ano.) forattinii, An. (Ano.) mattogrossensis, An. (Ano.) sp. nr. fluminensis, An. (Ker.) bambusicolus, An. (Ker.) lepidotus, An. (Lop.) squamifemur, An. (Nys.) sp. nr. konderi and three specimens of an undetermined species of Anopheles subgenus Stethomyia (Fig. S1, Supplementary data 3). The specific identification of three specimens as belonging to Anopheles subgenus Stethomyia, a new subgeneric record for Ecuador, was hampered as only two females remain. The only male exemplar, stored in ethanol, was wholly destroyed in an earlier DNA study and therefore its genitalia could not be examined. The two COI sequences obtained (Figure) (as Anopheles $\mathrm{sp}$. TIP1) were unique with regard to others in BOLD or GenBank, thus it remains unclear whether the specimens collected represent a new species or corresponds to one of the five already described species within the subgenus Stethomyia (An. acanthotorynus Komp, An. canorii Floch \& Abonnenc, An. kompi Edwards, An. nimbus (Theobald) or An. thomasi Shannon). While it was not possible to positively confirm the identity of the species detected here, COI sequence comparison with the three available Stethomyia species sequences have excluded An. acanthotorynus, An. kompi and An. nimbus. Comparative DNA sequences are not available for An. canorii or An. thomasi, however the former has only been reported from French Guiana so its presence in Ecuador seems unlikely. Mostly probably, these DNA sequences represent An. thomasi or perhaps a new species within the subgenera.

Anopheles (Ano.) fluminensis was originally described from Itaperuna, state of Rio de Janeiro, Brazil and has never been reported from Ecuador. Comparison of sequences from five specimens identified as "An. fluminensis?" by morphology showed $2.75-3.77 \%$ sequence differences from two unpublished Brazilian specimens of $A n$. fluminensis in the Mosquito Barcoding Initiative (MBI) dataset in BOLD (MBII823-09 and MBII825-09) from Pariquera Acú, state of São Paulo, Brazil. Retrospective comparisons with Brazilian specimens revealed morphological differences and the species, designated herein as An. sp. nr. fluminensis awaits formal description.

Six $C O I$ sequences were generated for specimens morphologically identified as "An. oswaldoi?". These clustered together, varying by only $0.2-0.61 \%$ over the 658-bp fragment, indicating these comprised the same species. Sequences were $99.01-100 \%$ identical to a new species determined from Colombia (Caquetá), Ecuador (Orellana) and Peru (Madre de Dios, Loreto) in RuizLopez et al. (2013) and 98.32\% identical to GenBank entry JF437965 (AC18-16 of Sallum \& Laporta from Acre Brazil, listed as An. konderi). The true identity of An. konderi remains unresolved. Efforts to resolve the molecular identity of An. konderi and An. oswaldoi (Ruiz-
Lopez et al. 2013) inadvertently uncovered the presence of more than one species in the specimens listed in the neotype description (Flores-Mendoza et al. 2004). Our specimens here correspond to one of the species barcoded from the neotype series, but it remains unclear whether this is "true" An. konderi. Efforts are underway to sequence the neotype, but in the meantime we designate this species $A n$. sp. nr. konderi [ = that of same name in Ruiz-Lopez et al. (2013)].

DNA barcodes are presented here for An. (Ano.) forattinii $(\mathrm{n}=1)$ for the first time. This is most similar to the published sequence of An. (Ano.) costai (95.1796.18\% identity, JX205127 and HM022403 from Colombia). Anopheles (Ano.) sp. nr. fluminensis, An. (Nys.) sp. nr. konderi, An. (Ano.) forattinii, An. (Ano.) mattogrossensis, An. (Lph.) squamifemur and the undetermined Anopheles (Ste.) species comprise six new country records for Anopheles in Ecuador.

Chagasia - Ch. bonneae was the only recognised species in the collection by morphology. DNA extractions and $C O I$ sequencing was carried out on nine purported Ch. bonneae specimens. Of these, two specimens were found to be highly genetically distinct (minimum $10.84 \%$ sequence divergence). Retrospective detailed morphological study confirmed morphological differences and showed this novel taxa was most similar to Ch. fajardoi, thus we informally designated this species $C h$. sp. nr. fajardoi $(\mathrm{n}=12)$. Mean intra-specific sequence variation ranged from $0 \%$ in Ch. sp. nr. fajardoi $(\mathrm{n}=2)$ to $1.3 \%$ in Ch. bonneae $(\mathrm{n}=7)$. These are the first available DNA barcodes for these two species.

Subfamily Culicinae - Tribe Aedini - Eight species of the Tribe Aedini were collected in this study, representing three genera and six subgenera, as follow: $H g$. (Hag.) janthinomys; Oc. (Chs.) fulvus, Oc. (Pcx.) serratus, Oc. (Pro.) argyrothorax; Ps. (Gra.) cingulata, Ps. (Jan.) albigenu, Ps. (Jan.) albipes and Ps. (Jan.) lanei (Fig. S1, Supplementary data 3). Oc. (Pro.) argyrothorax, Ps. (Jan.) albigenu and Ps. (Jan.) lanei are new country records for Ecuador.

Tribe Culicini - Twenty-six species of Tribe Culicini were collected in this study (Fig. S1, Supplementary data 3). Culex: twenty-five species of Culex were collected, representing five subgenera: $C x$. (And.) bamborum, $C x$. (And.) browni, Cx. (And.) sp. nr. conservator, Cx. (Car.) bonnei, Cx. (Car.) iridescens, Cx. (Car.) secundus, $C x$. (Car.) urichii, Cx. (Car.) wilsoni, Cx. (Cux.) bonneae, Cx. (Cux.) camposi, Cx. (Cux.) coronator s.l., Cx. (Cux.) mollis, $C x$. (Cux.) usquatus, Cx. (Mcx.) chryselatus, $C x$. (Mcx.) pleuristriatus, Cx. (Mcx.) stonei, Cx. (Mel.) eastor, Cx. (Mel.) elevator, Cx. (Mel.) evansae, Cx. (Mel.) iolambdis, Cx. (Mel.) pilosus, Cx. (Mel.) serratimarge, Cx. (Mel.) symbletos, Cx. (Mel.) theobaldi and Cx. (Mel.) vomerifer.

The most commonly encountered Culex species were Cx. (Cux.) mollis $(\mathrm{n}=181)$ and Cx. (Car.) urichii $(\mathrm{n}=141)$. Ten species of Culex are reported from Ecuador for the first time: $C x$. (And.) bamborum, $C x$. (Car.) iridescens, Cx. (Car.) wilsoni, Cx. (Cux.) bonneae, Cx. (Cux.) us- 
quatus, $C x$. (Mel.) serratimarge, Cx. (Mel.) symbletos, $C x$. (Mcx.) pleuristriatus and Cx. (Mcx.) stonei, including the newly discovered taxa $C x$. (And.) sp. nr. conservator (Supplementary data 2).

DNA barcodes were generated for five Culex species: $C x$. (And.) browni $(\mathrm{n}=1), C x$. (And.) sp. nr. conservator $(\mathrm{n}=1), C x$. (Car.) bonnei $(\mathrm{n}=2$; intra-specific distance, $0.15 \%), C x$. (Car.) urichii $[\mathrm{n}=6$; mean distance, $0.18 \%$ (range $0-0.46 \%$ ) and $C x$. (Mel.) serratimarge $(\mathrm{n}=$ 1)]. Mean intra-specific distances within Culex species ranged from $0-0.62 \%$ (mean $0.21 \%$ ) whereas inter-specific differences ranged from 9.0-15.69\% (mean 13\%). These sequences represent the first published DNA barcodes for all these species.

Culex (And.) sp. nr. conservator was discovered through DNA analysis. The sequence of one specimen, morphologically identified as $C x$. (And.) conservator, was compared against unpublished sequences in the MBI dataset generated from near topotypic specimens from Trinidad. These sequences differed by $9.46 \%$, confirming the novel taxa in Ecuador. The $C x$. (And.) browni COI sequence shared $96.77-96.93 \%$ sequence similarity with the unpublished MBI $C x$. (And.) conservator sequences from Trinidad. Culex (Car.) bonnei COI sequences were most similar to $C x$. (Car.) urichii (91.13-91.44\%, herein) and $C x$. (Mel.) serratimarge to $C x$. (Mel.) iolambdis (92.3-92.66\%) (MBI unpublished).

Fifty specimens were identified as belonging to the $C x$. (Cux.) coronator group. Of the six recognised species in this complex (Cx. covagarcia Forattini, $C x$. camposi Dyar, Cx. coronator Dyar \& Knab, Cx. ousqua Dyar, Cx. usquatus Dyar and Cx. usquatissimus Dyar) (Bram 1967), the presence of only Cx. camposi $(\mathrm{n}=2)$ and $C x$. usquatus $(\mathrm{n}=3)$ were verified through examination of slide-mounted male genitalia. The remaining specimens from Yasuní National Park and the group as a whole need further examination.

Lutzia - The 14 specimens of Lt. (Lut.) allostigma collected herein represent the first report of this species in Ecuador (Fig. S1, Supplementary data 3). Heinemann and Belkin (1979) previously reported an undetermined species of the genus (as Culex subgenus Lutzia), but it is unclear whether these were Lt. allostigma. All specimens collected here were found in water collected in Palm bracts on the ground or in Bamboo stumps filled with boiled leaf water (Fig. S1, Supplementary data 1). DNA barcodes were generated for three specimens of Lt. (Lut.) allostigma $(\mathrm{n}=3)$. Intra-specific variation ranged from $0.15-0.31 \%$ and was closest to the published sequence of Cx. (Cux.) hutchinsoni (DQ149239) at 93.45\% similarity.

Tribe Orthopodomyiini - Orthopodomyia: Three specimens of Or. fascipes were collected as immatures in a small tree hole $(\mathrm{n}=2, \mathrm{EC} 175)$ and one in the internode of fallen, living bamboo (EC197) (Fig. S1, Supplementary data 1,3 ).

Tribe Sabethini - Limatus: Two species of the genus Limatus were recorded: Li. durhamii and Li. flavisetosus; the latter is a new country record. Here we present the COI barcode data for Li. flavisetosus $(\mathrm{n}=1)$ for the first time. This is the first public barcode available for this species and while it $100 \%$ matched six undetermined specimens in BOLD, the next most similar unpublished sequence was that of $L i$. durhamii at 91.59-92.2\% similarity. Onirion: five specimens of On. imparis were reared from bamboo internodes (Supplementary data 1). Runchomyia: one female Ru. (Cte.) magna was identified, reared from a pupa collected in ground seepage (EC130). Sabethes: a new species, Sa. (Pey.) sp. nr. luxodens, was discovered as immatures in a bamboo internode (EC132, $\mathrm{n}=4$ ), along with an adult female, identifiable only to subgenus Sabethes (EC219). Trichoprosopon: Tr. digitatum $(\mathrm{n}=279)$ was the second most numerous species collected in this study. DNA barcodes were generated for two specimens of Tr. digitatum ( $0.62 \%$ difference); these comprise the first published Trichoprosopon COI sequences. Two specimens of a new species, Tr. sp. nr. lampropus were collected from water collected in a Palm bract, lying on the ground (Supplementary data 1, 3). Wyeomyia: due to lack of updated keys, species of the genus Wyeomyia are notoriously difficult to identify. Many Wyeomyia specimens have been identified only to subgenus and these specimens form part of a larger revisionary study of the genus by CHP. Of the 12 Wyeomyia species identified herein, six were new to science: $W y$. (Dec.) sp. CP2013, Wy. (Dod.) sp. nr. aphobema (identified by DNA), Wy. (Hys.) sp. nr. lamellata, Wy. (Mia.) sp. nr. codiocampa, Wy. (Wyo.) sp. nr. albosquamata and $W y$. (Wyo.) sp. nr. medioalbipes. Of the remaining six species [Wy. (Dec.) pseudopecten, Wy. (Dec.) ulocoma, Wy. (Dod.) aphobema, Wy. (Hys.) autocratica, Wy. (Mia.) codiocampa, Wy. (Mia.) oblita], all but Wy. (Dod.) aphobema are new country records for Ecuador (Fig. S1, Supplementary data 3).

DNA barcodes were generated for three species of Wyeomyia, namely: Wy. (Dec.) ulocoma $(\mathrm{n}=8$; mean distance 0.7 , range $0-1.55 \%), W y$. (Dod.) aphobema $(\mathrm{n}=$ 1) and $W y$. (Dod.) sp. nr. aphobema $(\mathrm{n}=1)$, with the latter discovered by DNA. Sequence variation between the three species sequenced ranged from 4.6-10.66\% (mean 9.94\%). These sequences comprise the first published COI barcodes for Wyeomyia species.

Tribe Toxorhynchitini - Toxorhynchites: Two species of the Toxorhynchites subgenus Lynchiella were identified: Tx. (Lyn.) bambusicola and Tx. (Lyn.) haemorrhoidalis. The three link-reared specimens of $T x$. (Lyn.) bambusicola reported here were collected in three separate collections (EC197, EC203, EC254) and these comprise a new country record for Ecuador (Fig. S1, Supplementary data 1). Only one DNA barcode was determined for an undetermined species of Toxorhynchites (as Toxorhynchites $\mathrm{sp}$. TIP1 in Figure). This sequence was most similar $(87.7 \%)$ to the published sequence of $T x$. (Tox.) splendens (HQ398877).

Tribe Uranotaeniini - Uranotaenia: The two male specimens of Ur. (Ura.) calosomata collected as pupae in the large lake (EC112) form another new country record (Fig. S1, Supplementary data 3). The DNA barcode sequenced from one of these specimens is closest to Ur. (Ura.) lateralis (HQ398881) at $89.14 \%$ sequence similarity. 
An integrated morphological and molecular approach such as advocated here facilitates robust identification for the species found in Amazonian Ecuador. DNA barcodes were useful in the discovery of several new species, which were at first overlooked by morphological assessment alone. Efforts will continue to obtain species-diagnostic DNA barcode signatures for all other species documented in this collection and elsewhere in Ecuador. A reference library of DNA sequences, generated from well-vouchered morphological specimens, will invariably facilitate the correct identification of adult specimens, the stage most commonly captured in vector surveillance studies and currently most difficult to identify using morphology alone.

Bionomics - Immature habitats - Mosquito species are often highly specific in their choice of oviposition site. In this study, larval habitats could be grouped into temporary and permanent groundwater habitats, artificial containers and natural (plant) containers (Fig. S1). Excepting An. (Ker.) bambusicola (exclusive to bamboo internodes) and An. (Ker.) lepidotus (exclusive to bromeliads), immatures of all other species of Anopheles and Chagasia were collected with ground water habitats: An. sp. nr. fluminensis was also found in a ground pool. Culex ( $\mathrm{Mel}$.) immatures were all recovered from ground water habitats, including ground pools, seepage and lake, swamp and stream margins (Fig. S1).

Permanent water bodies (lakes, swamps, stream margins) in the forest environs of the TBS yielded a high diversity of taxa. Species collected at the edge of the fourhectare lake (EC112, EC199, EC263) included An. (Ano.) mattogrossensis, An. (Nys.) sp. nr. konderi, Cx. (Mel.) pilosus, Cx. (Mel.) serratimarge, Cx. (Mel.) theobaldi, Cx. (Mel.) eastor, Cx. (Mel.) symbletos, Ur. (Ura.) calosomata and further undetermined specimens of An. (Ano.) and $C x$. (Mel.) (Fig. S1, Supplementary data 1). Eighteen collections carried out at stream margins (EC100, EC125, EC127, EC128, EC145, EC146, EC152, EC153, EC163, EC169, EC170, EC172, EC198, EC216, EC257, EC258, EC260, EC266) yielded immatures of the following taxa: An. (Ano.) sp. nr. fluminensis, An. (Lph.) squamifemur, An. (Nys.) sp. nr. konderi, Cx. (Mel.) elevator, Cx. (Mel.) evansae, Cx. (Mel.) iolambdis, Cx. (Mel.) theobaldi, Ch. bonneae, Ch. sp. nr. fajardoi and undetermined specimens of An. (Ano.) and An. (Ste.). Larvae of An. sp. nr. fluminensis, An. (Nys.) sp. nr. konderi, Cx. (Mel.) theobaldi and undetermined specimens of $C x$. (Mel.), An. (Ano.) and Chagasia were found at the edges of a large swamp (EC255, EC269). Ground pools (EC137, EC148, EC200) were occupied by An. (Ano.) sp. nr. fluminensis, Cx. (Cux.) coronator s.l., CX. (Mel.) evansae, Oc. (Pcx.) serratus, Ps. (Jan.) albigenu and undetermined specimens of Cx. (Mel.). Culex (Cux.) camposi, Cx. (Cux.) coronator s.l., Cx. (Cux.) usquatus, Cx. (Mel.) pilosus and Ru. (Cte.) magna were collected from ground seepage in open sunlight (EC130, EC134) (Fig. S1, Supplementary data 1).

Many species were found occupying a variety of natural and artificial habitats at ground level. Culex (And.) sp. nr. conservator, Cx. (Cux.) mollis, Cx. (Car.) urichii, Lt. (Lut.) allostigma, Li. durhamii, Li. flavisetosus,
Tr. digitatum and Tr. sp. nr. lampropus were collected in small rainwater pools in palm bracts on the ground (EC103, EC110, EC113-7, EC120-1, EC140-1, EC143, EC171, EC175, EC186-7, EC194). Culex (Cux.) mollis, Tr. digitatum and Wy. (Dod.) sp. nr. aphobema were collected from rainwater pockets in a folded tarpaulin on the forest floor (EC157). Larvae of Cx. (And.) browni, Cx. (And.) sp. nr. conservator, Cx. (Cux.) mollis, Li. flavisetosus and $T r$. digitatum were collected in a tree hole in a fallen tree (EC118). Larvae of Li. durhamii were collected in a discarded $1.5 \mathrm{~L}$ plastic bottle lying on the forest floor (EC188) in which rainwater had collected.

Dark plastic oviposition traps were placed at different heights up a tower in the forest: at ground level (EC209, EC212), at $5 \mathrm{~m}$ (EC210), at $8 \mathrm{~m}$ (EC164, EC167), at $25 \mathrm{~m}$ (EC213) and at the top of the tower (34 m, EC208). Tr. digitatum was collected in the oviposition cups (ovi-cup) placed at every height (EC167, EC208, EC209, EC210, EC213). An undetermined species of Toxorhynchites was reared from an ovi-cup (EC212) at ground level, $C x$. (Mcx.) pleuristriatus at $8 \mathrm{~m}$ (EC164) and Cx. (Mcx.) chryselatus and $T r$. digitatum were collected together in an ovi-cup placed $34 \mathrm{~m}$ up at the top of the tower (EC208).

Bamboo offers many discrete microhabitats for immature stages of forest mosquitoes; these microhabitats appear to be closely associated with certain mosquito species. Culex (Car.) bonnei and Cx. (Cux.) mollis were collected from inside bamboo into which a hole had been artificially cut (EC154) and from cut, dry bamboo lying on the ground (EC136), along with Li. durhamii, Li. sp. undet. and Li. flavisetosus. Split aged bamboo sections were filled with boiled leaf water and left on the forest floor to promote oviposition (EC177-181, EC183184, EC214-215, EC217). Culex (Cux.) mollis, Lt. (Lut.) allostigma, Tr. digitatum and Wy. (Dec.) ulocoma were reared from these containers. Culex (Car.) wilsoni, Cx. (Car.) iridescens, On. imparis, Tx. (Lyn.) bambusicola and Tx. (Lyn.) haemorrhoidalis were collected from internodes in dead bamboo (EC202-203, EC206, EC270) whereas An. (Ker.) bambusicolus, Cx. (And.) bamborum, Cx. (And.) browni, Cx. (Mcx.) pleuristriatus, Cx. (Car.) secundus, Cx. (Car.) urichii, Cx. (Car.) wilsoni, On. imparis, Sa. (Pey.) sp. nr. luxodens, Tx. (Lyn.) theobaldi, Wy. (Mia.) codiocampa and Wy. (Mia) oblita were collected from internodes in living bamboo (EC131-133, EC196, EC204). Tx. (Lyn.) bambusicola and Or. fascipes were collected from a bamboo internode in fallen, living bamboo (EC197) and Cx. wilsoni from a bamboo internode in fallen, cut bamboo (EC205). Li. durhamii, Li. flavisetosus and Tr. digitatum were collected from bamboo stumps (EC155, EC174, EC201) (Fig. S1, Supplementary data 1).

Anopheles mosquitoes of the subgenus Kertezsia breed almost exclusively in plant containers and serve as highly effective malaria vectors in forested areas (Zavortink 1973). Whereas An. (Ker.) bambusicolus (EC131, EC254) was collected from internodes in standing bamboo, we found that immatures of An. (Ker.) lepidotus were restricted to bromeliad axils (EC104, EC151, EC166, EC256). No details were noted for EC165, but as An. (Ker.) lepidotus was collected along with Tr. digi- 
tatum, it seems likely that this collection was also a bromeliad axil collected from the tower.

Water collections from bromeliad axils yielded a high diversity of mosquito species including: An. (Ker.) lepidotus, Cx. (Car.) urichii, Cx. (Car.) bonneae, Cx. (Mcx.) chryselatus, Cx. (Mcx.) stonei, Cx. (Mcx.) sp. undet., Tx. (Lyn.) bambusicola, Wy. (Dod.) aphobema, Wy. (Hys.) autocratica, Wy. (Hys.) sp. nr. lamellata, Wy. (Dec.) ulocoma, Wy. (Wyo.) sp. nr. albosquamata, Wy. (Wyo.) sp. nr. medioalbipes, Wy. (Dec.) sp. undet., Wy. (Hys.) sp. undet. and Wy. (Wyo.) sp. undet. (EC104-105, EC108, EC135, EC138, EC147, EC151, EC156, EC161, EC166, EC207, EC256, EC268). An. (Ker.) lepidotus, Cx. (Car.) bonneae, Cx. (Mcx.) chryselatus, Cx. (Mcx.) stonei, Cx. (Mcx.) sp. undet. and Tx. (Lyn.) bambusicola were all collected from bromeliad axils in high $(>30 \mathrm{~m})$ in the forest canopy (EC166, EC207, EC256), accessed from the tower and canopy walkway. Bromeliad axils that fall to the ground (EC122-123) seem to loose their exclusivity and are occupied instead by non-bromeliadspecific species such as Culex (Car.) bonnei, Cx. (Cux.) mollis, Cx. (Car.) urichii and Lt. (Lut.) allostigma, which appear to occupy almost all ground habitats. Excluding the fallen bromeliads, nine species were collected in this unique habitat, including three of the new Wyeomyia species.

Species found in the axils of Heliconia plants (EC106, EC107, EC144, EC158-160, EC173, EC189, EC193, EC195, EC218, EC264) were limited to Tr. digitatum and Wyeomyia (Dec.) species namely $W y$. (Dec.) pseudopecten, Wy. (Dec.) ulocoma, Wy. (Dec.) sp. CP2013 and Wy. (Dec.) sp. undet. Immatures of Tx. (Lyn.) haemorrhoidalis were found in the axil of a palm frond (EC267). Immatures of Cx. (Cux.) mollis, Hg. (Hag.) janthinomys, Oc. (Pro.) argyrothorax, Or. fascipes and Wy. (Dec.) ulocoma were collected in holes in living trees (EC111, EC142, EC162, EC173).

In addition, $C x$. (Car.) bonneae and $C x$. (Cux.) mollis females opportunistically laid egg rafts in rearing pans in the laboratory (EC149-150) (Supplementary data 1).

Adult collections - Due to the paucity of diagnostic female characteristics, little effort was placed on collection of adults so only 142 adults were collected in seven discrete collections. Three collections were carried out using Shannon traps (EC124, EC139, EC259), two human landing collections (EC126, EC168), one indoor resting (EC219) and one outdoor resting collection (EC127) (Supplementary data 1). Only those indisputable specific identifications are listed, with most adult females being identified to subgeneric level only (Supplementary data 3).

An un-baited Shannon trap set some $1.5 \mathrm{~m}$ above the ground (EC124) yielded only one Lt. allostigma, whereas setting the trap near a gas lantern resulted in the collection of many more specimens as well as a wider variety taxa $(\mathrm{EC} 259, \mathrm{n}=84)$ : $A n$. (Nys.) sp. nr. konderi, Cx. (Cux.) sp. undet., Cx. (Mel.) pilosus, Cx. (Mel.) theobaldi, Cx. (Mel.) vomerifer, $C x$. (Mel.) sp. undet., Hg. (Hag.) sp. undet., Oc. (Chs.) fulvus, Oc. sp. undet., Ps. (Jan.) albipes and Tr. digitatum. Another Shannon trap (EC139) set high in the forest canopy (c. $34 \mathrm{~m}$ at the top of the tower) collected Oc. (Chs.) fulvus, Tr. digitatum, Ps. (Jan.) albigenu and $C x$. (Cux.) sp. undet., as well as the only specimens of Ps. (Gra.) cingulata $(\mathrm{n}=1)$ and Ps. (Jan.) lanei $(\mathrm{n}=1)$ detected in this study (Supplementary data 1, 3).

Tr. digitatum was collected outdoor resting near the edge of a stream (EC127) and indoor resting within the research station, along with undetermined species of Cx. (Cux.) and Ps. (Jan.) and the only Sa. (Sab.) specimen collected in this study (EC219). An. (Ker.) lepidotus was collected on two separate occasions trying to bite the collectors some $34 \mathrm{~m}$ up in the canopy on the tower (EC126, EC168) (Supplementary data 1). Despite the unfocussed collecting effort, five of the 68 species reported (7.3\%) were collected only as adults, showing that adult collections are a valuable addition to biodiversity surveys in this region.

Current list of Ecuadorian Culicidae - Given the relatively narrow spatial and temporal range of this study, the biodiversity of mosquitoes collected was quite remarkable. That more $16 \%$ of all taxa identified from the Yasuní National Park in these snapshot collections were new to science and $54 \%$ are new country records clearly indicates that taxonomic study of Ecuadorian fauna has been woefully neglected, at least in the eastern Amazonian region. This prompted the authors to review the available literature and to determine a current faunal list for the mosquitoes of Ecuador (Supplementary data 2).

By far the most productive mosquito taxonomist in Ecuadorian history was Roberto Levi-Castillo, who published several species lists (Leví-Castillo 1945, 1949, 1953) and many new species in the 40s and 50s, 30 of which remain valid species today (Supplementary data 2). Levi-Castillo published several reports (e.g., LevíCastillo 1956) in which he listed species collected in Ecuador, but these were composite lists, without associated collection data or specimens. While there is no doubting his contribution to the understanding of the mosquito fauna of Ecuador, his disregard for preserving voucher specimens has previously been highlighted (e.g., Zavortink 1979a) (p. 13). In their revisionary work, "A Catalog of the Mosquitoes of the World", Knight and Stone (1977) included the distributions of only verifiable records.

To create this updated species list for Ecuador, we used Knight and Stone (1977) as a basis and included all species reported in verified peer reviewed publications since, reflecting revisions in taxonomy (Knight 1978, Faran 1979, Heinemann \& Belkin 1979, Zavortink 1979a, b, Berlin \& Belkin 1980, Sirivanakarn 1982, Ward 1984, Forattini \& Sallum 1989, Hall et al. 1999, Sallum \& Hutchings 2003, Reinert et al. 2004, 2005, 2006, 2008, 2009, Rueda et al. 2004, Harbach \& Howard 2007, González et al. 2010, Harrison et al. 2012, Ruiz-Lopez et al. 2013). Our findings show that 179 mosquito species have been recorded in Ecuador to date, representing 26 genera and 39 subgenera (Supplementary data 2). This is the first published list of Ecuadorian Culicidae since Leví-Castillo (1953) and we hope this serves as a useful systematics platform for future work on the mosquitoes of Ecuador. 


\section{ACKNOWLEDGEMENTS}

To Prof Kelly Swing and all the staff at the TBS, Universidad San Francisco de Quito, who made these collections possible and enjoyable. MBI sequences of An. fluminensis from Brazil used for molecular comparison here were provided by RCW and Dr Maria Anice Sallum. Samples of Cx. conservator were collected in Trinidad by Dr Shelley Cook [Natural History Museum (NHM), London]. These specimens were barcoded and submitted to the BOLD database as part of a collaborative study of Dr Ralph Harbach (PI) and Ian Kitching (both NHM) with Y-ML.

\section{REFERENCES}

Arnell JH 1973. Mosquito studies (Diptera, Culicidae) XXXII. A revision of the genus Haemagogus. Contrib Amer Ent Inst 10: 1-174.

Bass MS, Finer M, Jenkins CN, Kreft H, Cisneros-Heredia DF, McCracken SF, Pitman NCA, English PH, Swing K, Villa G, Di Fiore A, Voigt CC, Kunz TH 2010. Global conservation significance of Ecuador's Yasuní National Park. PLoS ONE 5: e8767.

Belkin JN, Schick RX, Galindo P, Aitken THG 1965. Mosquito studies (Diptera, Culicidae) I. A project for a systematic study of the mosquitoes of Middle America. II. Methods for the collection, rearing and preservation of mosquitoes. Contrib Amer Ent Inst 1: 1-78.

Berlin OG, Belkin JN 1980. Mosquito studies (Diptera, Culicidae). XXXVI. Subgenera Aedinus, Tinolestes and Anoedioporpa of Culex. Contrib Amer Ent Inst 17: 1-104.

Berlin OGW 1969. Mosquito studies (Diptera, Culicidae). XII. A revision of the Neotropical subgenus Howardina of Aedes. Contrib Amer Ent Inst 4: 1-190.

Bram RA 1967. The classification of the Culex subgenus Culex in the New World (Diptera, Culicidae). Proc US Nat Mus 120: 1-122.

Cova-Garcia P 1961. Notas sobre los anofelinos de Venezuela y su identificación, 2nd ed., Grafos, Caracas, 212 pp.

Faran ME 1979. The importance of an integrated approach in solving a problem in mosquito systematics. Mosq Syst 11: 280-288.

Faran ME 1980. Mosquito studies (Diptera: Culicidae) XXXIV. A revision of the Albimanus section of the subgenus Nyssorhynchus of Anopheles. Contrib Amer Ent Inst 15: 1-215.

Faran ME, Linthicum KJ 1981. A handbook of the Amazonian species of Anopheles (Nyssorhynchus) (Diptera: Culicidae). Mosq Syst 13: 1-81.

Felsenstein J 1985. Confidence limits on phylogenies: an approach using the bootstrap. Evolution 39: 783-791.

Flores-Mendoza CF, Peyton EL, Wilkerson RC, Lourenço-de-Oliviera R 2004. Anopheles (Nyssorhynchus) konderi Galvão and Damasceno: neotype designation and resurrection from synonymy with Anopheles (Nyssorhynchus) oswaldoi (Peryassu) (Diptera: Culicidae). Proc Entomol Soc Wash 106: 118-132.

Foley DH, Wilkerson RC, Rueda LM 2009. Importance of the "what", "when" and "where" of mosquito collection events. J Med Entomol 46: 717-722.

Folmer O, Black M, Hoeh W, Lutz R, Vrijenhoek R 1994. DNA primers for amplification of mitochondrial cytochrome c oxidase subunit from diverse metazoan invertebrates. Mol Mar Biol Biotechnol 3: 294-299.

Forattini OP, Sallum MAM 1989. Taxonomic study and redescription of Culex (Melanoconion) theobaldi (Lutz, 1904) (Diptera: Culicidae). Mem Inst Oswaldo Cruz 84 (Suppl. IV): 201-208.

Gaffigan T, Pecor J 1997. Collecting, rearing, mounting and shipping mosquitoes. Available from: wrbu.si.edu/Techniques.html.
González R, Carrejo N 2007. Introduccion al estudio taxonomico de Anopheles de Colombia claves y notas de distribucion, Universidad del Valle, Cali, 237 pp.

González R, Carrejo N, Wilkerson RC, Alarcon J, Alarcon-Ormasa J, Ruiz F, Bhatia R, Loaiza J, Linton Y-M 2010. Confirmation of Anopheles (Anopheles) calderoni Wilkerson, 1991 (Diptera: Culicidae) in Colombia and Ecuador through molecular and morphological correlation with topotypic material. Mem Inst Oswaldo Cruz 105: 1001-1009.

Guedes AS, Souza MA 1964. Sobre Psorophora (Janthinosoma) albigenu Lutz, 1908 e Psorophora (Janthinosoma) albipes (Theobald, 1907) (Diptera, Culicidae). Rev Bras Malariol Doenças Trop 16: 471-486.

Hall CR, Howard TM, Harbach RE 1999. Sabethes (Peytonulus) luxodens, a new species of Sabethini (Diptera: Culicidae) from Ecuador. Mem Inst Oswaldo Cruz 94: 329-338.

Harbach RE 1991. A new subgenus of the genus Sabethes (Diptera: Culicidae). Mosq Syst 23: 1-9.

Harbach RE, Howard TM 2007. Corrections in the status and rank of names used to denote varietal forms of mosquitoes (Diptera: Culicidae). Zootaxa 1542: 35-48.

Harbach RE, Howard TM 2009. Review of the genus Chagasia (Diptera: Culicidae: Anophelinae). Zootaxa 2210: 1-25.

Harbach RE, Peyton EL 2000. Systematics of Onirion, a new genus of Sabethini (Diptera: Culicidae) from the Neotropical region. Bull Nat Hist Mus Lond (Ent) 69: 115-169.

Harrison BA, Ruiz-Lopez F, Falero GC, Savage HM, Pecor JE, Wilkerson RC 2012. Anopheles (Kerteszia) lepidotus (Diptera: Culicidae), not the malaria vector we thought it was: Revised male and female morphology; larva, pupa and male genitalia characters, and molecular verification. Zootaxa 1: 1-17.

Heinemann SJ, Belkin JN 1979. Collection records of the project Mosquitoes of Middle America 13. South America: Brazil (BRA, BRAP, BRB), Ecuador (ECU), Peru (PER), Chile (CH). $J$ Am Mosq Control Assoc 11: 61-118.

Judd DD 1998. Review of a bromeliad-ovipositing lineage in Wyeomyia and the resurrection of Hystatomyia (Diptera: Culicidae). Ann Entomol Soc Am 91: 572-589.

Kimura M 1980. A simple method for estimating evolutionary rates of base substitutions through comparative studies of nucleotide sequences. J Mol Evol 16: 111-120.

Knight KL 1978. Supplement to A catalog of the mosquitoes of the world (Diptera: Culicidae), Entomological Society of America, College Park, 107 pp.

Knight KL, Stone A 1977. A catalog of the mosquitoes of the world (Diptera: Culicidae), 2nd ed., Vol. 6, The Thomas Say Foundation/Entomological Society of America, Baltimore, $621 \mathrm{pp}$.

Lane J 1953. Neotropical Culicidae, Vol. 2, Universidade de São Paulo, São Paulo, 565 pp.

Leví-Castillo R 1945. Los anofelinos de la República del Ecuador, Senefelder, Guayaquil, 172 pp.

Leví-Castillo R 1949. Lista provisional de los mosquitos Culex del Ecuador. Physis 20: 190-193.

Leví-Castillo R 1953. Lista provisional y distribución de los mosquitos Culicinos en el Ecuador. Rev Ecuat Ent Par 1: 34-45.

Leví-Castillo R 1956. A systematic note on Haemagogus spegazzinii Brethes, 1912. (Diptera - Culicidae). Proc Ent Soc Wash 58: 345-347.

Oxford P, Bish R, Swing K 2012. Yasuni, Tiputini and the web of life, Ingwe Press, Quito, 264 pp. 
Pecor JE, Mallampalli VL, Harbach RE, Peyton EL 1992. Catalog and illustrated review of the subgenus Melanoconion of Culex (Diptera: Culicidae). Contrib Amer Ent Inst 27: 1-228.

Reinert JF 2009. List of abbreviations for currently valid generic-level taxa in family Culicidae (Diptera). European Mosquito Bulletin 27: 68-76.

Reinert JF, Harbach RE, Kitching IJ 2004. Phylogeny and classification of Aedini (Diptera: Culicidae), based on morphological characters of all life stages. Zool J Linn Soc 142: 289-368.

Reinert JF, Harbach RE, Kitching IJ 2006. Phylogeny and classification of Finlaya and allied taxa (Diptera: Culicidae: Aedini) based on morphological data from all life stages. Zool J Linn Soc 148: $1-101$.

Reinert JF, Harbach RE, Kitching IJ 2008. Phylogeny and classification of Ochlerotatus and allied taxa (Diptera: Culicidae: Aedini) based on morphological data from all life stages. Zool J Linn Soc 153: 29-114.

Reinert JF, Harbach RE, Kitching IJ 2009. Phylogeny and classification of tribe Aedini (Diptera: Culicidae). Zool J Linn Soc 157: 700-794.

Reinert JF, Harbach RE, Sallum MAM 2005. Checklist of the Aedine mosquito species (Diptera, Culicidae, Aedini) occurring in Middle and South America (South of the United States) reflecting current generic and subgeneric status. Rev Bras Entomol 49: 249-252.

Rozeboom LE, Komp WHW 1950. A review of the species of Culex of the subgenus Melanoconion (Diptera, Culicidae). Ann Entomol Soc Am 43: 75-114.

Rueda LM, Peyton EL, Manguin S 2004. Anopheles (Anopheles) pseudopunctipennis Theobald (Diptera: Culicidae): neotype designation and description. J Med Entomol 41: 12-22.

Ruiz-Lopez F, Wilkerson RC, Ponsonby DJ, Herrera M, Sallum MAM, Velez ID, Quiñones ML, Flores-Mendoza C, Chadee D, Alarcon J, Alarcon-Ormasa J, Linton Y-M 2013. Systematics of the Oswaldoi complex (Anopheles, Nyssorhynchus) in South America. Parasit Vectors 6: 324.

Saitou N, Nei M 1987. The neighbour-joining method: a new method for reconstructing phylogenetic tress. Mol Biol Evol 4: 406-425.

Sallum MAM, Forattini OP 1996. Revision of the spissipes section of Culex (Melanoconion) (Diptera: Culicidae). J Am Mosq Control Assoc 12: 517-600.

Sallum MAM, Hutchings RSG 2003. Taxonomic studies on Culex (Melanoconion) coppenamensis Bonne-Wepster \& Bonne (Dip- tera: Culicidae) and description of two new species from Brazil. Mem Inst Oswaldo Cruz 98: 615-622.

Schick RX 1970. Mosquito studies (Diptera, Culicidae) XX. The terrens group of Aedes (Finlaya). Contrib Amer Ent Inst 5: 1-158.

Sirivanakarn S 1979. A new species of Culex (Melanoconion) from Bolivia and Ecuador (Diptera: Culicidae). Mosq Syst 11: 135-138.

Sirivanakarn S 1982. A review of the systematics and a proposed scheme of internal classification of the New World subgenus Melanoconion of Culex (Diptera, Culicidae). Mosq Syst 14: 265-338.

Stone A 1944. Notes on the genus Trichoprosopon (Diptera, Culicidae). Revista de Entomologia 15: 335-341.

Tamura K, Peterson D, Peterson N, Stecher G, Nei M, Kumar S 2011. MEGA5: molecular evolutionary genetics analysis using maximum likelihood, evolutionary distance and maximum parsimony methods. Mol Biol Evol 28: 2731-2739.

Valencia JD 1973. Mosquito studies (Diptera, Culicidae). XXXI. A revision of the subgenus Carollia of Culex. Contrib Amer Ent Inst 9: $1-134$.

Ward RA 1984. Second supplement to a catalog of the mosquitoes of the world (Diptera: Culicidae). Mosq Syst 16: 227-270.

Wilkerson RC, Sallum MAM 1999. Anopheles (Anopheles) forattinii: a new species in series Arribalzagia (Diptera: Culicidae). $J$ Med Entomol 36: 345-354.

Zapata-Ríos G, Suárez RE, Utreras BV, Vargas OJ 2006. Evaluación de amenazas antropogénicas en el Parque Nacional Yasuní y sus implicaciones para la conservación de mamíferos silvestres. Lyonia 10: 31-41.

Zavortink TJ 1972. Mosquito studies (Diptera, Culicidae). XXVIII. The new world species formerly placed in Aedes (Finlaya). Contrib Amer Ent Inst 8: 1-206.

Zavortink TJ 1973. Mosquito studies (Diptera, Culicidae) XXIX. A review of the subgenus Kerteszia of Anopheles. Contrib Amer Ent Inst 9: 1-54.

Zavortink TJ 1979a. The new sabethine genus Johnbelkinia and a preliminary reclassification of the composite genus Trichoprosopon. Contrib Amer Ent Inst 17: 1-61.

Zavortink TJ 1979b. A reclassification of the sabethine genus Trichoprosopon. Mosq Syst 11: 255-257.

Zavortink TJ, Chaverri LG 2009. Resurrection of the names Toxorhynchites moctezuma (Dyar \& Knab) and Toxorhynchites hypoptes (Knab) from synonymy with Toxorhynchites theobaldi (Dyar \& Knab) (Diptera: Culicidae). Proc Entomol Soc Wash 111: 890-897. 


\begin{tabular}{|c|c|c|c|c|c|c|c|c|c|c|c|c|c|c|c|c|c|c|c|c|c|c|c|c|c|c|c|c|c|c|}
\hline Species $(\mathrm{n}=68)$ & 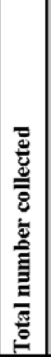 & 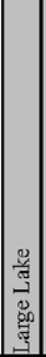 & 帘 & 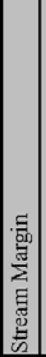 & $\begin{array}{l}\overrightarrow{8} \\
\vdots \\
\vdots \\
\overline{5} \\
\overline{5} \\
5\end{array}$ & 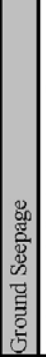 & 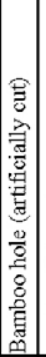 & 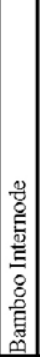 & 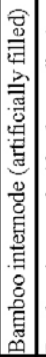 & 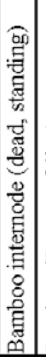 & 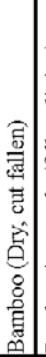 & 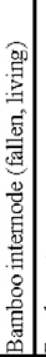 & & 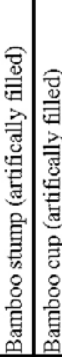 & 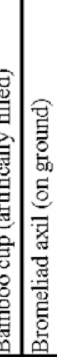 & 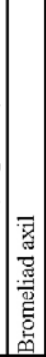 & 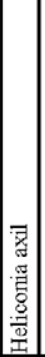 & 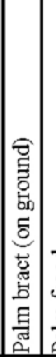 & 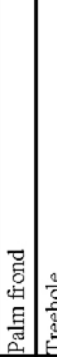 & & 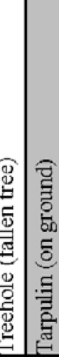 & 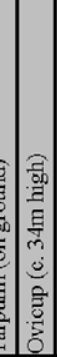 & 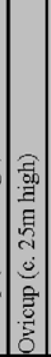 & 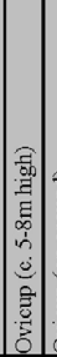 & 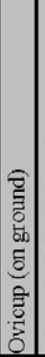 & & 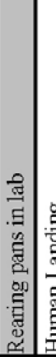 & 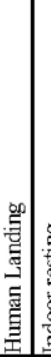 & م. & \\
\hline An. (Ano.) forattinii & 13 & & & + & & & & & & & & & & & & - & & + & & 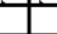 & 7 & 千 & & & & + & + & & & \\
\hline An. (Ano.) mattogrossensis & 1 & + & & & & & & & & & & & & & & & & & & & & & & & & & & & & \\
\hline An. (Ano.) sp. nr. fluminensis & 83 & & + & + & 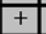 & & & & & & & & & & & & & & & & & & & & & & & & & \\
\hline An. (Ker.) bambusicolus & 7 & & & & & & & + & & & & & & & & & & & & & & - & & & & & & & & \\
\hline \begin{tabular}{|l|} 
An. (Ker.) lepidotus \\
\end{tabular} & 34 & & & & & & & & & & & & & & & + & & . & & 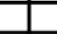 & 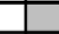 & + & & & & & \pm & + & & \\
\hline An. (Lph.) squamifemur & 9 & & & + & & & & & & & & & & & & & & & & & & & & & & & & & & \\
\hline An. (Nys.) sp. nr. konderi & 154 & + & + & + & & & & & & & & & & & & & & & & & & & & & & & & & & + \\
\hline An. (Ste.) sp. undet. & 3 & & & + & & & & & & & & & & & & & & . & & & & W & & & & & & & & \\
\hline Ch. bonneae & 97 & & & + & & & & & & & & & & & & & & & & & & & & & & & & & & \\
\hline Ch. sp. nr. fajardoi & 12 & & & + & & & & & & & & & & & & & & & & & & & & & & & & & & \\
\hline C.x. (And) bamborum & 7 & & & & & & & + & & & & & & & & & & & & & & & & & & & & & & \\
\hline Cx. (And.) browni & 2 & & & & & & & + & & & & & & & & & & & & + & + & 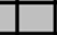 & & & & & & & & \\
\hline$C x .(A n d)$ sp. nr. conservator & 38 & & & & & & & & & & & & & & & & & + & & + & + & & & & & & & & & \\
\hline Cx. (Car.) bonnei & 36 & & & & & & + & & & & + & & & & + & & & & & & & & & & & & & & & \\
\hline Cx. $($ Car. $)$ iridescens & 4 & & & & & & & & & + & & & & & & & & & & & & & & & & & & & & \\
\hline Cx. (Car.) secundus & 4 & & & & & & & + & & & & & & & & & & & & & & - & & & & & & & & \\
\hline Cx. (Car.) urichii & 141 & & & & & & & + & & & & & & & + & + & & + & & & & & & & & & & & & \\
\hline Cx. (Car.) wilsoni & 23 & & & & & & & + & & + & + & & & & & & & & & & & & & & & & & & & \\
\hline Cx. (Cux.) bonneae & 21 & & & & & & & & & & & & & & & & & & & & & + & & & & & + & & & \\
\hline Cx. (Cux.) camposi & 3 & & & & & + & & & & & & & & & & & & 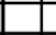 & & & & $\square$ & & & & & $\square$ & & & \\
\hline Cx. $($ Cux. $)$ coronator s.l. & 50 & & & & + & 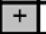 & & & & & & & & & & & & & & & & & & & & & & & & \\
\hline \begin{tabular}{|l|l} 
Cx. (Cux) mollis \\
\end{tabular} & 181 & & & & & & + & & & & + & & & + & + & & & + & & $+5+$ & +5 & & & & & & + & & & \\
\hline Cx. (Cux.) usquatus & 2 & & & & & + & & & & & & & & & & & & & & & & & & & & & & & & \\
\hline Cx. (Mcx.) chryselatus & 22 & & & & & & & & & & & & & & & + & & & & & & + & & & & & & & & \\
\hline$C x .(M c x$.$) pleuristriatus$ & 11 & & & & & & & + & & & & & & & & & & & & & & + & & & & & & & & \\
\hline Cx. (Mcx.) stonei & 1 & & & & & & & & & & & & & & & & & & & & & + & & & & & & & & \\
\hline Cx. (Mel.) eastor & 4 & + & & & & & & & & & & & & & & & & & & & & & & & & & & & & \\
\hline
\end{tabular}




\begin{tabular}{|c|c|c|c|c|c|c|c|c|c|c|c|c|c|c|c|c|c|c|c|c|c|c|c|c|c|c|c|c|c|c|c|c|}
\hline Species $(n=68)$ & 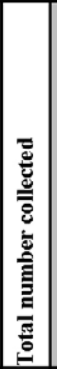 & 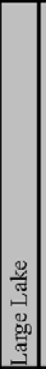 & : & 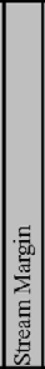 & $\begin{array}{l}\overline{0} \\
\overline{8} \\
\bar{z} \\
\overline{\mathbf{z}} \\
\overline{0} \\
0\end{array}$ & 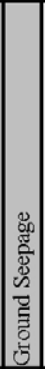 & 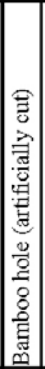 & 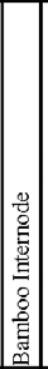 & 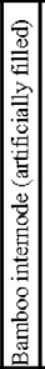 & 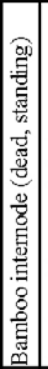 & 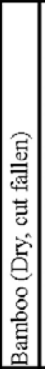 & 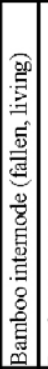 & 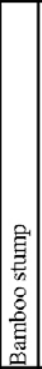 & 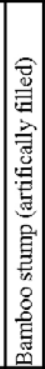 & 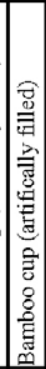 & 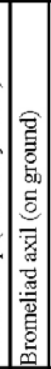 & 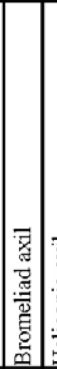 & 㴗 & 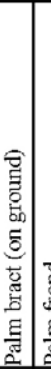 & 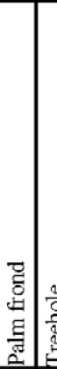 & & 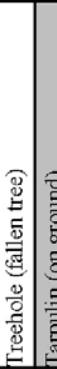 & & 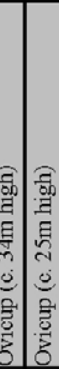 & 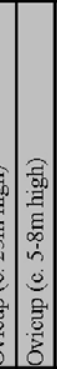 & 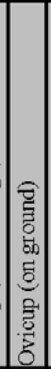 & 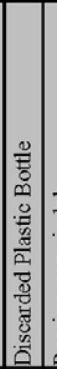 & 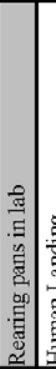 & & & 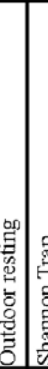 & \\
\hline Cx. (Mel.) elevator & 45 & & & + & & & & & & & & & & & & & & & & & & & & & & & & & & & & \\
\hline Cx. (Mel.) evansae & 8 & & & + & + & & & & & & & & & & & & & & & & & - & & & & & - & & & & & \\
\hline$C x .($ Mel. $)$ iolambdis & 5 & & & + & & & & & & & & & & & & & & & & & 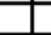 & 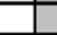 & & & & & 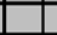 & & & & & \\
\hline Cx. (Mel.) pilosus & 18 & + & & & & + & & & & & & & & & & & & & & & & & & & & & & & & & & \\
\hline Cx. (Mel) serratimarge & 19 & & & & & & & & & & & & & & & & & & & & & & & & & & & & & & & \\
\hline Cx. (Mel.) symbletos & 2 & \begin{tabular}{|llll}
+ \\
\end{tabular} & & & & & & & & & & & & & & & & & & & & & & & & & E & & & & & \\
\hline Cx. (Mel.) theobaldi & 9 & +5 & + & + & & & & & & & & & & & & & & & & & & 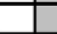 & & & & & 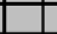 & & & & 7 & \\
\hline$C x$ (Mel.) vomerifer & 1 & & & & & & & & & & & & & & & & & & & & & & & & & & & & & & \pm & + \\
\hline Hg. (Hag.) janthinomys & 1 & & & & & & & & & & & & & & & & & & & & + & & & & & & & & & & & \\
\hline Li. durhamii & 61 & & & & & & & & & & + & & + & & & & & & + & & - & & & & & _- & + & & & & & \\
\hline Li. flavisetosus & 29 & & & & & & & & & & + & & + & & & & & & + & & & + & & & & & & & & & & \\
\hline Lt. (Lut.) allostigma & 14 & & & & & & & & & & & & & + & & & & & + & & & & & & & & & & & & z & \\
\hline Oc. (Chs.) fulvus & 27 & & & & & & & & & & & & & & & & & & & & & & & & & & & & & & 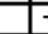 & \\
\hline Oc. $(P c x$.$) serratus$ & 5 & & & & + & & & & & & & & & & & & & & & & & & & & & & & & & & & \\
\hline Oc. (Pro.) argyrothorax & 2 & & & & & & & & & & & & & & & & & & & & + & & & & & & & & & & & \\
\hline On. imparis & 5 & & & & & & & + & & + & & & & & & & & & & & 5 & & & & & & & & & & 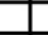 & \\
\hline Or. fascipes & 3 & & & & & & & & & & & + & & & & & & & & & + & & & & & & & & & & & \\
\hline Ps. (Gra.) cingulata & 1 & & & & & & & & & & & & & & & & & & & & & & & & & & & & & & z & \pm \\
\hline Ps. (Jan.) albigenu & 4 & & & & $\begin{array}{llll}+ \\
\end{array}$ & & & & & & & & & & & & & & & & & & & & & & & & & & 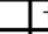 & \\
\hline Ps. (Jan.) albipes & 1 & & & & & & & & & & & & & & & & & & & & & & & & & & & & & & -7 & \\
\hline Ps. (Jan.) lanei & 1 & & & & & & & & & & & & & & & & & & & & & & & & & & & & & & - & \\
\hline Ru. (Cte.) magna & 1 & & & & & + & & & & & & & & & & & & & & & & & & & & & & & & & & \\
\hline Sa. (Pey) sp. nr. luxodens & 4 & & & & & & & + & & & & & & & & & & & & & & & & & & & & & & & & \\
\hline$S a$ (Sab.) sp. undet. & 1 & & & & & & & & & & & & & & & & & & & & & & & & & & & & & & L & \\
\hline Tx. (Lyn.) bambusicola & 3 & & & & & & & & & \begin{tabular}{|lll}
+ \\
\end{tabular} & & + & & & & & & & & & & & & & & & & & & & & \\
\hline Tx. (Lyn.) haemorrhoidalis & 9 & & & & & & & & & + & & & & & & & & & & + & & & & & & & & & & & & \\
\hline Tr. digitatum & 279 & & & & & & & & + & & & & + & + & + & & & + & + & & & +5 & ++ & \begin{tabular}{c|c}
+ & + \\
\end{tabular} & + & $1+$ & & & & & + & \\
\hline
\end{tabular}




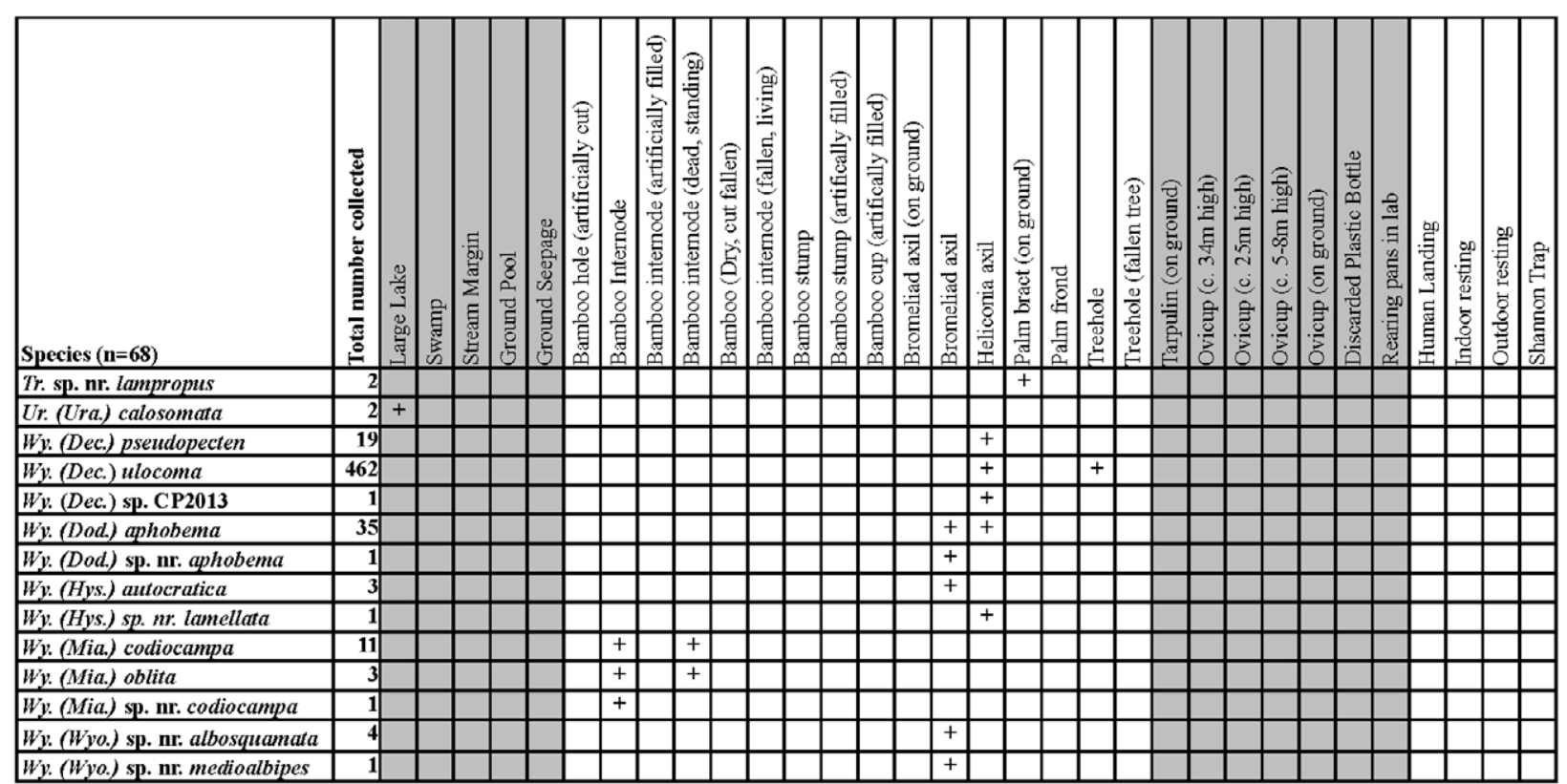

Fig. S1: mosquito taxa identified from forest habitat in the Ecuadorian Amazon, detailing diversity in larvae habitats and adult collections methodology. Some 68 unique taxa, representing 17 genera and 27 subgenera and 12 species new to science, were collected in this study. Two undetermined species representing new subgeneric records for Anopheles (Stethomyia) and Sabethes (Sabethes) are also included. Subgeneric abbreviations are given in parenthesis. Anopheles sp. nr. konderi is the same taxa as in Ruiz-Lopez et al. (2013). Undetermined species within the Culex coronator group: males of $C x$. camposi and $C x$. usquatus have been unequivocally confirmed using slide-mounted genitalia and are listed separately. 


\section{Habitat details and associated species per collection}

All collections were carried out in the environs of the TBS by RCW. Coordinates are given in square brackets. Redundancies are removed.

1998

EC100. Harpía Trail 750 m: stream margin, slow clear water, heavy shade. 29.x.1998. Cx. (Mel.) elevator [-0.630607, $-76.145393]$.

EC103. Harpía Trail 100 m: fallen palm bract. 29.x.1998. Cx. (Car.) urichii [-0.637087, -76.150089].

EC104. Tower: bromeliad axil. 29.x.1998. An. (Ker.) lepidotus, Wy. (Wyo.) sp. nr. medioalbipes [-0.638056, $-76.145000]$.

EC105. (as EC104) Cx. (Mcx.) chryselatus, Wy. (Hys.) autocratica.

EC106. Main camp: Heliconia axil. 29.x.1998. Wy. (Dec.) ulocoma [-0.637087, -76.150089].

EC107. (as EC106) Wy. (Dec.) ulocoma, Wy. (Dec.) sp. undet.

EC108. (as EC106) 30.x.1998. Wy. (Dec.) pseudopecten, Wy. (Dod.) aphobema, Wy. (Dec.) sp. undet., Wy. (Hys.) sp. nr. lamellata.

EC110. Murciélago Trail 250 m: fallen palm bract. 30.x.1998. Cx. (And.) sp. nr. conservator, Cx. (Car.) urichii [-0637082, -76.143910].

EC111. Nr Lake: small tree hole. 31.x.1998. Hg. (Hag.) janthinomys [-0.637087, -76.150089].

EC112. Lake (c. 4 hectares): partial shade, emergent grasses. 31.x.1998. An. (Nys.) sp. nr. konderi, Cx. (Mel.) eastor, Cx. (Mel.) serratimarge, Cx. (Mel.) symbletos, Cx. (Mel.) sp. undet., Ur. (Ura.) calosomata [-0.637087, -76.150089].

EC113. (as EC111) Fallen palm bract. Cx. (Car.) urichii, Cx. (Cux.) mollis.

EC114. (as EC113) Cx. (Car.) urichii, Lt. (Lut.) allostigma.

EC115. (as EC113) Cx. (Car.) urichii, Li. flavisetosus.

EC116. (as EC113) Cx. (Car.) urichii, Cx. (Cux.) mollis.

EC117. Lago Trail 2,200 m: fallen palm bract. 31.x.1998. Tr. digitatum [-0.636056, -76.164249].

EC118. Lago Trail 2,000 m: tree hole in fallen tree. 31.x.1998. Cx. (And.) browni, Cx. (And.) sp. nr. conservator, Cx. (Cux.) mollis, Li. flavisetosus, Tr. digitatum [-0.637650, -76.164393].

EC120. Lago Trail 1,700 m: fallen palm bract. 31.x.1998. Cx. (Car.) urichii, Cx. (Cux.) mollis, Li. durhamii, Li. flavisetosus $[-0.637255,-76.162151]$.

EC121. Lago Trail 1,500 m: fallen palm bract. 31.x.1998. Cx. (Car.) urichii, Cx. (Cux.) mollis, Lt. (Lut.) allostigma $[-0.637495,-76.160425]$.

EC122. (as EC121) Cx. (Car.) urichii, Cx. (Cux.) mollis, Lt. (Lut.) allostigma.

EC123. (as EC121) Bromeliad axil fallen on ground. An. (Ano.) sp. undet., Cx. (Car.) bonnei, Cx. (Car.) urichii, Cx. (Cux.) mollis.

EC124. (as EC106) Shannon Trap. 01.xi.1998. Lt. (Lut.) allostigma.

EC125. Harpía Trail $750 \mathrm{~m}$ : stream margin, heavy shade, in leaves and debris. 01.xi.1998. An. (Ano.) sp. nr. fluminensis, An. (Ano.) squamifemur, An. (Ste.) sp. undet. (as EC128), Cx. (Mel.) elevator, Cx. (Mel.) iolambdis, Ch. sp. nr. fajardoi [-0.630607, -76.145393].

EC126. (as EC104) human landing. 01.xi.1998. An. (Ker.) lepidotus.

EC127. Harpía Trail 800 m: stream margin, heavy shade, turbid water. 02.xi.1998. An. (Ano.) sp. nr. fluminensis (immatures), Tr. digitatum (adult resting) [-0.630179, -76.145504].

EC128. Harpía Trail 1,500 m, stream margin, turbid water. 02.xi.1998. An. (Ano.) sp. nr. fluminensis, An. (Ano.) forattinii, An. (Nys.) sp. nr. konderi, An. (Ste.) sp. undet. (as EC125), Cx. (Mel.) elevator [-0.625633, -76.147785].

EC130. Nr. Rio Tiputini (c. $8 \mathrm{~km}$ from Tiputini Biodiversity Station): seepage area (1 m x $3 \mathrm{~m}$ ), standing, turbid water in direct sunlight. 03.xi.1998. Cx. (Cux.) coronator s.l., Cx. (Mel.) pilosus, Cx. (Cux.) camposi, Ru. (Cte.) magna [-0.664722, -76.215000].

EC131. (as EC130) Bamboo internode. An. (Ker.) bambusicolus, Cx. (And.) bamborum.

EC132. (as EC131) Sa. (Pey.) sp. nr. luxodens, Wy. (Mia.) codiocampa, Wy. (Mia.) sp. nr. codiocampa, Wy. (Mia.) sp. undet.

EC133. (as EC131) Cx. (And.) bamborum, Cx. (And.) browni, Cx. (Car.) urichii, Wy. (Mia.) oblita.

EC134. (as EC130) Seepage area (0.5 m x $0.5 \mathrm{~m}$ x $0.05 \mathrm{~m}$ deep), clear water in direct sunlight. $C x$. (Cux.) coronator s.l., Cx. (Cux.) camposi, Cx. (Cux.) usquatus.

EC135. (as EC106) Bromeliad axil. 03.xi.1998. Cx. (Car.) urichii, Wy. (Dod.) aphobema, Wy. (Wyo.) sp. nr. albosquamata, Wy. (Wyo.) sp. undet.

EC136. (as EC135) Dry, cut bamboo on ground. Cx. (Car.) bonnei, Cx. (Cux.) mollis, Li. durhamii, Li. flavisetosus, Li. sp. undet.

EC137. (as EC135) Small shallow ground pool, turbid water in direct sunlight. Cx. (Cux.) coronator s.l.

EC138. (as EC135) Wy. (Dod.) aphobema. 
EC139. Tower: Shannon trap. 02.xi.1998. Cx. (Cux.) sp. undet., Oc. (Chs.) fulvus, Ps. (Gra.) cingulata, Ps. (Jan.) albigenu, Ps. (Jan.) lanei, Tr. digitatum [-0.664720, -76.215000].

EC140. Only georeference and habitat data recorded, fallen palm bract. 04.xi.1998. Cx. (Car.) urichii [-0.635830, $-76.159720]$.

EC141. (as EC140) Cx. (Cux.) mollis.

EC142. (as EC140) Small tree hole. Oc. (Pro.) argyrothorax.

EC143. (as EC140) Cx. (Cux.) mollis.

EC144. (as EC140) Heliconia axil. Wy. (Dec.) pseudopecten.

EC145. (as EC140) Small stream margin (c.1 m), in floating leaves and debris, clear water, heavy shade. An. (Ano.) sp. nr. fluminensis, An. (Nys.) sp. nr. konderi, Cx. (Mel.) elevator.

EC146. (as EC140) Small stream margin (c.2 m), in floating leaves and debris, clear water, heavy shade. An. (Ano.) sp. nr. fluminensis, Cx. (Mel.) evansae.

EC147. Guacamayo Trail 2,300 m: bromeliad axil. 04.xi.1998. Wy. (Dod.) aphobema, Wy. (Wyo.) sp. nr. albosquamata, Wy. (Wyo.) sp. undet. [-0.634005, -76.163853].

EC148. (as EC147) ground pool at base of fallen tree (1 m x $2 \mathrm{~m}$ x $0.05 \mathrm{~m}$ ). An. (Ano.) sp. nr. fluminensis, Cx. (Mel.) evansae, Cx. (Mel.) sp. undet., Oc. (Pcx.) serratus, Ps. (Jan.) albigenu.

EC149. (as EC106) eggs laid in rearing pan inside laboratory. 04.xi.1998. Cx. (Cux.) bonneae.

EC150. (as EC149) Cx. (Cux.) mollis.

EC151. (as EC104) 04.xi.1998. An. (Ker.) lepidotus.

EC152. Harpía Trail 800 m: small stream margin (c.1m wide), slow-moving clear water, heavy shade, no aquatic vegetation. 05.xi.1998. An. (Ano.) sp. nr. fluminensis, Cx. (Mel.) elevator [-0.634076, -76.145346].

EC153. Harpía Trail $350 \mathrm{~m}$ : stream margin (c.3 m wide), moderate flow, clear water, heavy shade, no aquatic vegetation. 05.xi.1998. Ch. sp. nr. fajardoi [-0.630179, -76.145504].

EC154. (as EC106) Water collected in artificially cut hole in bamboo, partial shade. 07.xi.1998. Cx. (Car.) bonnei, Cx. (Cux.) mollis.

EC155. (as EC154) Bamboo stump. Li. durhamii.

EC156. (as EC154) Bromeliad axil. Wy. (Dod.) aphobema, Wy. (Dod.) sp. nr. aphobema.

EC157. Numa Trail: water in folded tarpaulin on ground. 07.xi.1998. Cx. (Cux.) mollis, Tr. digitatum [-0.637638, $-76.149807]$.

EC158. (as EC154) Heliconia axil. Wy. (Dec.) ulocoma, Wy. (Dec.) sp. undet.

EC159. (as EC158) Wy. (Dec.) ulocoma, Wy. (Dec.) sp. undet.

EC160. (as EC158) Wy. (Dec.) ulocoma, Wy. (Dec.) sp. undet.

EC161. (as EC156) Wy. (Dec.) ulocoma, Wy. (Dec.) sp. undet., Wy. (Dod.) aphobema.

EC162. Chorong Trail: tree hole. 07.xi.1998. Cx. (Cux.) mollis [-0.636352, -76.148723].

EC163. Matapalo Trail $450 \mathrm{~m}$ : small stream margin. 07.xi.1998. An. (Ano.) sp. nr. fluminensis [-0.6367530, $-76.147343]$.

EC164. (as EC104) Oviposition cup c. $34 \mathrm{~m}$ up tower. 07.xi.1998. Cx. (Mcx.) pleuristriatus.

EC165. (as EC164) An. (Ker.) lepidotus, Tr. digitatum.

EC166. (as EC164) An. (Ker.) lepidotus, Cx. (Cux.) bonneae, Cx. (Mcx.) chryselatus, Cx. (Mcx.) stonei.

EC167. (as EC104) Oviposition cup c. $8 \mathrm{~m}$ up tower. 07.xi.1998. Tr. digitatum.

EC168. (as EC104) 07.xi.1998. Human landing. An. (Ker.) lepidotus.

EC169. Rio Tiputini, Blackwater area (c. $3.5 \mathrm{~km}$ from Tiputini Biodiversity Station): large stream margin (c. $15 \mathrm{~m}$ wide) leading to flooded area, turbid water, partial shade. 08.xi.1998. An. (Ano.) sp. nr. fluminensis, An. (Lph.) squamifemur, An. (Nys.) sp. nr. konderi, Ch. bonneae [-0.638333, -76.181944].

EC170. Harpía Trail 750 m: small stream margin, semi-permanent, slow-moving, heavy shade. 10.xi.1998. An. (Ano.) sp. nr. fluminensis, Ch. bonneae, Ch. sp. nr. fajardoi [-0.630607, -76.145393].

EC171. Harpía Trail $50 \mathrm{~m}$ : fallen palm bract. 10.xi.1998. Li. flavisetosus.

EC172. Matapalo Trail $450 \mathrm{~m}$ : small stream margin, semi-permanent, slow-moving, heavy shade. 10.xi.1998. An. (Ano.) sp. nr. fluminensis, Ch. bonneae [-0.637530, -76.147343].

EC173. (as EC172) Tree hole. Wy. (Dec.) ulocoma.

EC174. (as EC106) Bamboo stump, partial shade. 07.xi.1998. Tr. digitatum [-0.637087, -76.150089].

EC175. (as EC106) Fallen palm bract. 11.xi.1998. Li. flavisetosus.

EC176. Canopy walkway: tree hole c. $30 \mathrm{~m}$ up. 11.xi.1998. Or. fascipes [-0.637461, -76.143517].

EC177. Main Camp at Chorongo Trail: aged bamboo internode, filled with boiled leaf water. 11.xi.1998. Tr. digitatum [-0.636352, -76.148723].

EC178. (as EC177) Aged bamboo stump filled with boiled leaf water. Tr. digitatum.

EC179. (as EC177) Tr. digitatum.

EC180. (as EC177) Tr. digitatum.

EC181. (as EC177) Tr. digitatum.

EC183. Main Camp at river: aged bamboo stump filled with boiled leaf water. 11.xi.1998. Cx. (Cux.) mollis. 
EC184. (as EC183) Tr. digitatum.

EC186. (as EC106) Fallen palm bract. 11.xi.1998. Tr. digitatum.

EC187. Lago Trail $975 \mathrm{~m}$ : fallen palm bract. 12.xi.1998. Tr. digitatum [-0.638058, -76.156169].

EC188. Lago Trail 1,400 m: discarded 1.5L water bottle. 12.xi.1998. Li. durhamii. [-0.637483, -76.159573].

EC189. (as EC188) Heliconia axil. Tr. digitatum, Wy. (Dec.) sp. undet.

EC193. Lago Trail 1,500 m: Heliconia axil. 12.xi.1998. Wy. (Dec.) sp. CP2013, Wy. (Dec.) sp. undet. [-0.637495, $-76.160425]$.

EC194. Lago Trail $975 \mathrm{~m}$ : fallen palm bract. 12.xi.1998. Tr. sp. nr. lampropus [-0.638058, -76.156169].

EC195. (as EC106) Heliconia axil. 12.xi.1998. Wy. (Dec.) pseudopecten, Wy. (Dec.) sp. undet.

EC196. Maquisapa Trail 6,200 m: Bamboo internode. 13.xi.1998. Cx. (Car.) wilsoni, Cx. (Mcx.) pleuristriatus [-0.631914, -76.166213].

EC197. (as EC196) Internode in fallen, living ba mboo. Tx. (Lyn.) bambusicola, Or. fascipes.

EC198. Maquisapa Trail 6,300 m: small stream margin (c.2m wide), slow-moving turbid water, heavy shade, in floating leaves and debris. 13.xi.1998. Cx. (Mel.) elevator [-0.632510, -76.165543].

EC199. (as EC112) 13.xi.1998. Cx. (Mel.) pilosus, Cx. (Mel.) theobaldi.

EC200. Maquisapa Trail 7,200 m: ground pool (1 m x $1 \mathrm{~m}$ ), clear, standing water, heavy shade, no aquatic vegetation.

13.xi.1998. An. (Ano.) sp. nr. fluminensis [-0.631914, -76.166213].

EC201. (as EC196) Bamboo stump. 13.xi.1998. Li. flavisetosus.

EC202. (as EC201) Internode in dead bamboo. On. imparis.

EC203. (as EC202) Tx. (Lyn.) bambusicola.

EC204. (as EC202) Wy. (Mia.) codiocampa, Wy. (Mia.) oblita.

EC205. (as EC201) Internode in fallen, cut bamboo. Cx. (Car.) wilsoni.

EC206. (as EC201) Internode in dead standing bamboo. Cx. (Car.) wilsoni.

EC207. (as EC104) Bromeliad axil, c. $30 \mathrm{~m}$ up in tree. 14.xi.1998. Cx. (Mcx.) chryselatus, Cx. (Mcx.) sp. undet., Wy.

(Hys.) sp. undet.

EC208. (as EC104) Oviposition cup, c. 34 m up tower. 14.xi.1998. Cx. (Mcx.) chryselatus, Tr. digitatum.

EC209. (as EC104) Oviposition cup, at base of tower. 14.xi.1998. Tr. digitatum.

EC210. (as EC104) Oviposition cup, c. $5 \mathrm{~m}$ up tower. 14.xi.1998. Tr. digitatum.

EC212. (as EC209) Tx. (Lyn.) sp. undet.

EC213. (as EC104) Oviposition cup, c.25 m up tower. 14.xi.1998. Tr. digitatum [-0.638058, -76.156169].

EC214. (as EC106) Aged bamboo cup filled with boiled leaf water. 16.xi.1998. Tr. digitatum.

EC215. (Exact location unknown) 17.xi.1998. Wy. (Dec.) ulocoma.

EC216. (as EC169) Large stream leading to swampy area, permanent turbid water, partial shade. 17.xi.1998. An.

(Ano.) sp. nr. fluminensis, An. (Lph.) squamifemur, An. (Nys.) sp. nr. konderi, Ch. bonneae, Cx. (Mel.) theobaldi.

EC217. Nr Main Camp: bamboo stump filled with boiled leaf water. 18.xi.1998. Lt. (Lut.) allostigma, Tr. digitatum [-0.37087, -76.150089].

EC218. (as EC106) Heliconia axil. 20.xi.1998. Wy. (Dec.) ulocoma, Wy. (Dec.) sp. undet.

EC219. (as EC106) Adults collected resting inside laboratory. 13.xi.1998. Cx. (Cux.) sp. undet., Ps. (Jan.) sp. undet.,

Sa. (Sab.) sp. undet., Tr. digitatum.

1999

EC254. Rio Tiputini (6 km from Tiputini Biodiversity Station): bamboo internodes (c.15). 25.v.1999. An. (Ker.) bambusicolus, Cx. (And.) bamborum, Cx. (Car.) secundus, On. imparis, Tx. (Lyn.) bambusicola [-0.663889, $-76.215558]$.

EC255. Rio Tiputini, Blackwater area (nr Tiputini Biodiversity Station): large swampy area (c.10 hectares), permanent slow-moving clear water, partial shade. 26.v.1999. An. (Ano.) sp. undet, An. (Nys.) sp. nr. konderi, Cx. (Mel.) theobaldi, Ch. sp. undet. [-0.638333, -76.181944].

EC256. (as EC104) Bromeliad axils (c.10), nr top of $32 \mathrm{~m}$ tower. 26.v.1999. An. (Ker.) lepidotus, Cx. (Mcx.) sp. undet., $C x$. (Mel.) sp. undet., Tx. (Lyn.) sp. undet.

EC257. Harpía Trail $750 \mathrm{~m}$ : small stream margin (c.1 m wide), permanent slow-moving clear water, heavy shade, in floating leaves and debris. 27.v.1998. Ch. sp. nr. fajardoi [-0.630607, -76.145393].

EC258. (as EC257) Ch. bonneae.

EC259. (as EC106) Shannon trap by gas lantern. 29.v.1998. Adult collection: An. (Nys.) sp. nr. konderi, Cx. (Cux.) sp. undet., Cx. (Mel.) pilosus, Cx. (Mel.) sp. undet., Cx. (Mel.) theobaldi, Cx. (Mel.) vomerifer, Hg. (Hag.) sp. undet., Oc. (Chs.) fulvus, Oc. sp. undet., Ps. (Jan.) albipes, Tr. digitatum.

EC260. Guacamayo Trail $550 \mathrm{~m}$ : small stream margin (c.1 m wide), permanent, slow-moving clear water, heavy shade. 29.v.1999. Ch. bonneae [-0.634476, -76.153932].

EC263. Lake (c. 4 hectares): permanent, standing turbid water, partial shade. 29.v.1999. An. (Ano.) mattogrossensis, An. (Ano.) sp. undet. [-0.636111, -76.165000]. 
EC264. (as EC106) Heliconia axils (c. 70 inflorescences). 31.v.1999. Wy. (Dec.) ulocoma, Tr. digitatum.

EC266. Chorongo Trail 1,100 m: small stream margin (c.1 m wide), permanent slow-moving clear water, heavy shade. An. (Ano.) forattinii [-0.635344, -76.151358].

EC267. Chorongo Trail $800 \mathrm{~m}$ : palm frond, heavy shade. 01.vi.1999. Tx. (Lyn.) haemorrhoidalis [-0.633068, $-76.150561]$.

EC268. Chorongo Trail 375 m: bromeliad axil. 01.vi.1999. Wy. (Dod.) aphobema, Cx. (Mcx.) sp. undet. [-0.633657, -76.148298].

EC269. Maquisapa Trail 5,300 m: large swamp, permanent standing clear water, heavy shade, in debris. 02.vi.1999. An. (Nys.) sp. nr. konderi, An. (Ano.) sp. nr. fluminensis, Cx. (Mel.) sp. undet. [-0.626363, -76.170037].

EC270. (as EC196) Internode in dead bamboo. 02.vi.1999. Tx. (Lyn.) haemorrhoidalis, Cx. (Car.) iridescens. 


\section{Family Culicidae Meigen, 1818}

\section{Subfamily Anophelinae Grassi, 1900}

\section{Genus Anopheles (An.) Meigen, 1818}

Subgenus Anopheles (Ano.) Meigen, 1818

apicimacula Dyar \& Knab, 1906

calderoni Wilkerson, 1991

eiseni Coquillett, 1902

forattinii Wilkerson \& Sallum, 1999

mattogrossensis Lutz \& Neiva, 1911

mediopunctatus Lutz, 1903

pseudopunctipennis Theobald, 1901

punctimacula Dyar \& Knab, 1906

sp. nr. fluminensis

Subgenus Kerteszia (Ker.) Theobald, 1905

bambusicolus Komp, 1937

boliviensis (Theobald, 1905)

cruzii Dyar \& Knab, 1908

lepidotus Zavortink, 1973

neivai Howard, Dyar \& Knab, 1913

Subgenus Lophopodomyia (Lph.) Antunes, 1937

gomezdelatorrei Levi-Castillo, 1955

squamifemur Antunes, 1937

Subgenus Nyssorhynchus (Nys.) Blanchard, 1902

albimanus Wiedemann, 1820

aquasalis Curry, 1932

darlingi Root, 1926

oswaldoi B [see Ruíz-Lopez et al. (2013)]

rangeli Gabaldon, Cova Garcia \& Lopez, 1940

sp. nr. konderi

triannulatus (Neiva \& Pinto, 1922)

trinkae Faran, 1979

Subgenus Stethomyia (Ste.) Theobald, 1902

sp. undet.

Genus Chagasia (Ch.) Cruz, 1906

bathana (Dyar, 1928)

bonneae Root, 1927

sp. nr. fajardoi

\section{Subfamily Culicinae Meigen, 1818}

Tribe Aedeomyiini Theobald, 1901

Genus Aedeomyia (Ad.) Theobald, 1901

Subgenus Aedeomyia (Ady.) Theobald, 1901

squamipennis (Lynch Arribálzaga, 1878) 
Tribe Aedini Neveu-Lemaire, 1902

Genus Georgecraigius (Gc.) Reinert, Harbach \& Kitching, 2006 Subgenus Horsfallius (Hor.) Reinert, Harbach \& Kitching, 2006 fluviatilis (Lutz, 1904)

Genus Haemagogus (Hg.) Williston, 1896

Subgenus Haemagogus (Hag.) Williston, 1896

acutisentis Arnell, 1973

boshelli Osorno-Mesa, 1944

janthinomys Dyar, 1921

lucifer (Howard, Dyar \& Knab, 1913)

panarchys Dyar, 1921

soperi Levi-Castillo, 1955

spegazzinii Brethés, 1912

Genus Howardina (Hw.) Theobald, 1903

brevivittata (Berlin, 1969)

ecuadoriensis (Berlin, 1969)

sexlineata (Theobald, 1901)

Genus Ochlerotatus (Oc.) Lynch Arribálzaga, 1891 milleri (Dyar, 1922)

Subgenus Chrysoconops (Chs.) Goeldi, 1905 fulvus (Wiedemann, 1828)

Subgenus Culicelsa (Cul.) Felt, 1904 taeniorhynchus (Wiedemann, 1821)

Subgenus Ochlerotatus (Och.) Lynch Arribálzaga, 1891

angustivittatus (Dyar \& Knab, 1907)

meprai (Martinez \& Prosen, 1953)

scapularis (Rondani, 1848)

Subgenus Protoculex (Pcx.) Felt, 1904

hastatus (Dyar, 1922)

nubilus (Theobald, 1903)

serratus (Theobald, 1901)

Genus 'Ochlerotatus' (Oc.) sensu auctorum of Reinert et al.

Subgenus 'Protomacleaya' (Pro.) sensu auctorum of Reinert et al. argyrothorax (Bonne-Wepster \& Bonne, 1920) metoecopus (Dyar, 1925)

Genus Psorophora (Ps.) Robineau-Desvoidy, 1827 Subgenus Grabhamia (Gra.) Theobald, 1903 cingulata (Fabricius, 1805)

Subgenus Janthinosoma (Jan.) Lynch Arribálzaga, 1891 albigenu (Peryassú, 1908) albipes (Theobald, 1907) ferox (von Humboldt, 1819)

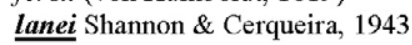
lutzii (Theobald, 1901)

Subgenus Psorophora (Pso.) Robineau-Desvoidy, 1827 
cilipes (Fabricius, 1805)

lineata (von Humboldt, 1819)

Genus Sallumia (Sl.) Reinert, Harbach \& Kitching, 2008

horator (Dyar \& Knab, 1907)

Genus Stegomyia (St.) Theobald, 1901

Subgenus Stegomyia (Stg.) Theobald, 1901

aegypti (Linnaeus, 1762)

Tribe Culicini Meigen, 1818

Genus Culex (Cx.) Linnaeus, 1758

Subgenus Aedinus (Ads.) Lutz, 1904

amazonensis (Lutz, 1905)

Subgenus Anoedioporpa (And.) Dyar, 1923

bamborum Rozeboom \& Komp, 1948

browni Komp, 1936

sp. nr. conservator

Subgenus Carrollia (Car.) Lutz, 1905

babahoyensis Levi-Castillo, 1953

bihaicola Dyar \& Núñez Tovar, 1928

bonnei Dyar, 1921

iridescens (Lutz, 1905)

infoliatus Bonne-Wepster \& Bonne, 1920

secundus Bonne-Wepster \& Bonne, 1920

urichii (Coquillett, 1906)

wilsoni Lane \& Whitman, 1943

Subgenus Culex (Cux.) Linnaeus, 1758

archegus Dyar, 1929

articularis Philippi, 1865

bonneae Dyar \& Knab, 1919

camposi Dyar, 1925

chidesteri Dyar, 1921

dolosus (Lynch Arribálzaga, 1891)

guayasi Leví-Castillo, 1953

levicastilloi Lane, 1945

mollis Dyar \& Knab, 1906

nigripalpus Theobald, 1901

quinquefasciatus Say, 1823

quitensis Levi-Castillo, 1953

usquatissimus Dyar, 1922

usquatus Dyar, 1918

Subgenus Melanoconion (Mel.) Theobald, 1903

adamesi Sirivanakarn \& Galindo, 1980

bastagarius Dyar \& Knab, 1906

batesi Rozeboom \& Komp, 1948

comminutor Dyar, 1920

conspirator Dyar \& Knab, 1906

distinguendus Dyar, 1928

dunni Dyar, 1918 
eastor Dyar, 1920

educator Dyar \& Knab, 1906

eknomios Forattini \& Sallum, 1992

elevator Dyar \& Knab, 1906

erraticus (Dyar \& Knab, 1906)

evansae Root, 1927

iolambdis Dyar, 1918

lucifugus Komp, 1936

ocossa Dyar \& Knab, 1919

oedipus Root, 1927

pedroi Sirivanakarn \& Belkin, 1980

penai Sirivanakarn, 1979

pilosus (Dyar \& Knab, 1906)

psatharus Dyar, 1920

putumayensis Matheson, 1934

saramaccensis Bonne-Wepster \& Bonne, 1920

serratimarge Root, 1927

spissipes (Theobald, 1903)

sursumptor Dyar, 1924

symbletos Sallum \& Hutchings, 2003

theobaldi (Lutz, 1904)

vomerifer Komp, 1932

Subgenus Microculex (Mcx.) Theobald, 1907

chryselatus Dyar \& Knab, 1919

imitator Theobald, 1903

pleuristriatus Theobald, 1903

stonei Lane \& Whitman, 1943

Subgenus Phenacomyia (Phc.) Harbach \& Peyton, 1992

corniger Theobald, 1903

Genus Deinocerites (De.) Theobald, 1901

pseudes Dyar \& Knab, 1909

Genus Galindomyia (Ga.) Stone \& Barreto, 1969

leei Stone \& Barreto, 1969

Genus Lutzia (Lt.) Theobald, 1903

Subgenus Lutzia (Lut.) Theobald, 1903

allostigma Howard, Dyar \& Knab, 1915

Tribe Mansoniini Belkin, 1962

Genus Coquillettidia (Cq.) Dyar, 1905

Subgenus Rhynchotaenia (Rhy.) Brethés, 1910

arribalzagae (Theobald, 1903)

fasciolata (Lynch Arribálzaga, 1891)

lynchi (Shannon, 1931)

Genus Mansonia (Ma.) Blanchard, 1901

Subgenus Mansonia (Man.) Blanchard, 1901

indubitans Dyar \& Shannon, 1925 
titillans (Walker, 1848)

Tribe Orthopodomyiini Belkin, Heinemann \& Page, 1970

Genus Orthopodomyia (Or.) Theobald, 1904

fascipes (Coquillett, 1906)

Tribe Sabethini Blanchard, 1905

Genus Johnbelkinia (Jb.) Zavortink, 1979

longipes (Fabricius, 1805)

ulopus (Dyar \& Knab, 1906)

Genus Limatus (Li.) Theobald, 1901

andinus Levi-Castillo, 1954

asulleptus (Theobald, 1903)

durhamii Theobald, 1901

flavisetosus de Oliveira Castro, 1935

guayasi Levi-Castillo, 1954

Genus Onirion (On.) Harbach \& Peyton, 2000

imparis Peyton \& Harbach, 2000

Genus Runchomyia (Ru.) Theobald, 1903

Subgenus Ctenogoeldia (Cte.) Edwards, 1930

magna (Theobald, 1905)

Genus Sabethes (Sa.) Robineau-Desvoidy, 1827

Subgenus Peytonulus (Pey.) Harbach, 1991

luxodens Hall, Howard \& Harbach, 1999

sp. nr. Luxodens

Subgenus Sabethes (Sab.) Robineau-Desvoidy, 1827 bipartipes Dyar \& Knab, 1906

Subgenus Sabethoides (Sbo.) Theobald,

chloropterus (von Humboldt, 1819)

Genus Trichoprosopon (Tr.) Theobald, 1903

andinum Levi-Castillo, 1953

compressum Lutz, 1905

digitatum (Rondani, 1848)

sp. nr. Lampropus

vonplesseni (Dyar \& Knab, 1906)

Genus Wyeomyia (Wy.) Theobald, 1901

aequatorianna Leví-Castillo, 1954

amazonica Levi-Castillo, 1954

flui (Bonne-Wepster \& Bonne, 1920)

Subgenus Decamyia (Dec.) Dyar

pseudopecten Dyar \& Knab, 1906

ulocoma (Theobald, 1903)

sp. CP2013

Subgenus Dendromyia (Den.) Theobald, 1903 
complosa (Dyar, 1938)

Subgenus Dodecamyia (Dod.) Dyar, 1919

aphobema Dyar, 1918

sp. nr. aphobema

Subgenus Hystatomyia (Hys.) Dyar, 1919

autocratica Dyar \& Knab, 1906

esmeraldasi (Levi-Castillo, 1955)

sp. nr. Lamellata

Subgenus Miamyia (Mia.) Dyar, 1919

codiocampa Dyar \& Knab, 1907

oblita (Lutz, 1904)

sp. nr. codiocampa

Subgenus Wyeomyia (Wyo.) Theobald, 1901

arthrostigma (Lutz, 1905)

chalcocephala Dyar \& Knab, 1906

melanocephala Dyar \& Knab, 1906

sp. nr. albosquamata

sp. nr. medioalbipes

Tribe Toxorhynchitini Lahille, 1904

Genus Toxorhynchites (Tx.) Theobald, 1901

Subgenus Lynchiella (Lyn.) Lahille, 1904

bambusicola (Lutz \& Neiva, 1913)

haemorrhoidalis (Fabricius, 1787)

hypoptes Knab, 1907

Tribe Uranotaeniini Lahille, 1904

Genus Uranotaenia (Ur.) Lynch Arribálzaga, 1891

Subgenus Uranotaenia (Ura.) Lynch Arribálzaga, 1891

aequatorianna Leví-Castillo, 1953

autocratica Dyar \& Knab, 1906

calosomata Dyar \& Knab, 1907

geometrica Theobald, 1901

leucoptera (Theobald, 1907)

lowii Theobald, 1901

pulcherrima Lynch Arribalzaga, 1891

typhlosomata Dyar \& Knab, 1907

Revised systematic checklist of 179 species of Ecuadorian Culicidae. Species listed include those published since the last major revision of world taxa by Knight and Stone (1977) (Knight 1978, Faran 1979, Heinemann \& Belkin 1979, Sirivanakarn 1979, Zavortink 1979a, b, Berlin \& Belkin 1980, Ward 1984, Forattini \& Sallum 1989, Hall et al. 1999, Sallum \& Hutchings 2003, Reinert et al. 2004, 2005, 2006, 2008, 2009, Rueda et al. 2004, Harbach \& Howard 2007, Zavortink \& Chaverri 2009, González et al. 2010, Harrison et al. 2012, Ruiz-Lopez et al. 2013). Species identified in this study are underlined; those underlined and in boldface comprise 37 new additions to the mosquito records from Ecuador. The 12 new species determined in this study are indicated. The classification used here follows that of Zavortink (1979a, b), Reinert et al. (2004, 2005, 2006, 2008, 2009) and Harbach and Howard (2007). 


\section{Voucher specimens examined}

Morphological identifications are listed alphabetically by genus, subgenus and species. Undetermined specimens are listed as "sp. undet." under the relevant generic or subgeneric heading. Specimens are listed both by collection number, e.g., EC118 and unique rearing number, e.g., EC118-003. Numbers and letters following these codes indicate the presence of associated larval "Le" and/or pupal "Pe" exuviae. Exuviae denoted in rounded brackets, e.g. (LePe) indicate skins are unmounted; all others are slide mounted. Whole larvae are indicated by "L". Sex is indicated by "M" for male and " $F$ " for female, where this information was not deducible a "?" is used. Square brackets [e.g. (M)] indicate that this life stage was preserved in ethanol for DNA studies. Current generic and subgeneric placement and abbreviations follow Reinert et al. (2005), Reinert (2009) and the abbreviation summary on the WRBU website (mosquitocatalog.org/abbreviations.aspx). Specimens for which DNA barcodes have been generated are followed by their respective BOLD and GenBank accessions in parenthesis.

Anopheles - An. (Ano.) forattinii ( $\mathrm{n}=13$ ), EC128-100Pe[M] (WRBUE070-10; KF670990); EC266[L], EC266001(LePe)[?], EC266-002(LePe)[M], EC266-003(LePe)M, EC266-004(LePe)F, EC266-005(LePe)F, EC266-006(LePe)F, EC266-007(LePe)F, EC266-008(LePe)F, EC266-100(Pe)F, EC266-101(Pe)F, EC266-102(Pe)M; An. (Ano.) mattogrossensis ( $\mathrm{n}=1$ ), EC263-002LePeF; An. (Ano.) sp. nr. fluminensis $(\mathrm{n}=83)$, EC125-001LePeF, EC125-002LePeM, EC125-003LePeF, EC125-004LePeF, EC125-005LePeF, EC125-006LePeF, EC125-007LePeM, EC125009LePeF, EC125-010LePeM, EC125-011LePeF, EC125-014LePeF, EC125-101PeF, EC125-106PeF, EC125-110PeF, EC127-001LePeF, EC127-002LePeM, EC127-100PeM, EC128-001LePeF, EC128-002LePeM, EC128-101Pe[M] Gen01/64 (MBII891-09; KF670994), EC128-102PeM, EC128-103PeF, EC128-104Pe[M], EC128-106Pe[M] (WRBUE083-10; KF670996), EC128-115PeF, EC128-116PeM, EC145-001LePeF, EC145-003LePeM, EC145-004LePeM, EC145-005LePeM, EC145-102PeF, EC146-001LePeM, EC146-002LePeM, EC146-003LePeF, EC146-005LePeF, EC148-001LePeF, EC148-002LePeF, EC148-003LePeF, EC148-004LePeF, EC148-005LePeM, EC148-008LePeM, EC148-100Pe[M] (WRBUE084-10; KF670995), EC148-104Pe[M] (WRBUE089-10; KF670992), EC152-001LePeM, EC152-002LePeF, EC152-003LePeM, EC152-004LePeF, EC152-005LePeF, EC152-006LePeF, EC152-007LePeF, EC152-008LePeM, EC152-009LePeF, EC152-100PeM, EC152-102PeF, EC152-103PeM, EC163-001LePeM, EC169-011LePe[F], EC170-001LePeM, EC170-002LePeF, EC170-005LePeF, EC172-001LePeF, EC172-002LePe[M] (WRBUE116-10; KF670993), EC200-001LePeF, EC200-002LePeF, EC200-003LePeM, EC200-004LePeM, EC200005LePeF, EC200-006LePeF, EC200-007LePeF, EC200-008LePeF, EC200-100PeF, EC200-101PeF, EC216-117PeF, EC216-118PeF, EC216-124PeF, EC216-146PeF, EC269-005LePeF, EC269-006LePeM, EC269-015LePeF, EC269-016LePeM, EC269-017LePe[?], EC269-107PeF, EC152-010LePe[M]; An. (Ano.) sp. undet. (n = 4), EC123-006LePeM, EC255-002LePe[M], EC255-007LePe[M], EC263[L]; An. (Ker.) bambusicolus (n = 7), EC131-001LePeMGen01/63, EC254-003LePe[M]Gen01/58, EC254-004LePe[M]Gen01/59, EC254-009LePeM, EC254-012LePeM, EC254-103PeF, EC254-106PeF; An. (Ker.) lepidotus ( $\mathrm{n}=34$ ), EC104-002LePeF, EC104-003LePe, EC126(A)[F] (WRBUE07910; KF670991), EC151-001LePe[M]Gen99/01 (MBII893-09; JQ041286), EC151-002LePeM, EC151-003LePeM, EC151-004LePeM, EC151-005LePe[M]Gen99/02 (LEPHO001-11; JQ041283), EC151-009LePeM, EC151-010LePeM, EC151-100PeF, EC151-101PeM, EC151-102PeF, EC151-103PeM, EC165-102(Pe)[M], EC166-002LePeF, EC166003LePeF, EC166-004PeMGen99/05, EC166-006LePeF, EC166-101PeMGen99/03, EC166-102PeMGen99/04 (LEPHO002-11; JQ041285), EC168a[F] (MBII894-09; JQ041282), EC168b[F] (MBII895-09; JQ041284), EC168[F], EC168[F], EC168[F], EC207-002LePeM, EC256-001LePeF, EC256-002LePeF, EC256-003LePeF, EC256-104PeM, EC256-105PeF, EC256-106PeM, EC256-107PeM; An. (Lph.) squamifemur (n = 9), EC125-107Pe[M]Gen01/65, EC169-001LePe[M], EC169-132PeM, EC169-133Pe[M]Gen01/66, EC216-013LePeF, EC216-017LePeM, EC216-018LePe[F], EC216-019LePeF, EC216-020LePeF; An. (Nys.) sp. nr. konderi $(\mathrm{n}=154)$, EC112-008LePeF, EC128-117PeMGen01/132 (WRBUE114-10; KF670997), EC145-002LePe[M] (WRBUE101-10; KF670998), EC169-002(LePe) [F] (WRBUE105-10; KF671001), EC169-004LePe[M] (WRBUE109-10; KF671002), EC169-005(LePe)F, EC169-007LePe[M] (WRBUE112-10; KF671000), EC169-008LePeM, EC169-012(LePe)F, EC169-013LePeM, EC169-014(LePe) F, EC169-015LePeM, EC169-126(Pe)[M] (WRBUE111-10; KF670999), EC216[8L], EC216-001LePeF, EC216-002LePeF, EC216-003LePeF, EC216-004LePeF, EC216-005LePeF, EC216-006LePeF, EC216-007LePeF, EC216-008LePeF, EC216-009LePeF, EC216-010LePe[M]Gen01/68, EC216-011LePeF, EC216-012LePeF, EC216-014LePeF, EC216-015LePeM, EC216-016LePeF, EC216-021LePeM，EC216-022LePeF，EC216-023LePeF，EC216-100PeF, EC216-104PeM, EC216-105PeM, EC216-106PeF, EC216-108Pe[M], EC216-109PeF, EC216-110Pe[M], EC216-111PeF, EC216-112PeM, EC216-113PeM, EC216-114PeM, EC216-115Pe[M]Gen01/67, EC216-116PeF, EC216-119PeF, EC216-120PeF, EC216-121PeF, EC216-122Pe[M], EC216-123PeF, EC216-125PeM, EC216-126PeF, EC216-127PeF, EC216-128PeF, EC216-129PeM, EC216-130PeM, EC216-135PeF, EC216-136PeF, EC216-137PeM, EC216-138PeF, EC216-140PeF, EC216-141Pe[M], EC216-142PeM, EC216-143PeM, EC216-144PeF, EC216-147PeF, EC216-148PeF, EC216-149PeM, EC216-150PeF, EC255[20L], EC255[30L], EC255-001LePe[M], EC255-003LePe[M], EC255-004LePeM, EC255-005LePeF, EC255-006LePeM, EC255-008LePeF, EC255-009LePeM, EC255-010LePeF, EC255011LePeF, EC255-012LePeF, EC255-013LePeM, EC255-014LePeM, EC255-015LePeF, EC255-016LePeF, EC255104PeF, EC255-105PeM, EC255-106(Pe)M, EC255-107(Pe)F, EC259(1F), EC269-001LePeM, EC269-007LePeF, 
EC269-008LePeF, EC269-009LePeF, EC269-010LePeF, EC269-014LePeF，EC269-018LePeM，EC269-103PeF, EC269-106PeF; An. (Nys.) sp. undet. (n = 3), EC269-100Pe[?], EC269-101Pe[?], EC269-102Pe[?]; An. (Ste.) sp. undet. $(\mathrm{n}=3), \mathrm{EC125-103Pe[M]} \mathrm{(WRBUE074-10;} \mathrm{KF671003),} \mathrm{EC125-105Pe[F]} \mathrm{(WRBUE081-10;} \mathrm{KF671004),} \mathrm{EC128-109-}$ PeF.

Chagasia - Ch. bonneae (n = 97), EC169[30L], EC169-003LePeF, EC169-006(LePe)F, EC169-009LePeM, EC169-010(LePe)F, EC169-100Pe[M] (WRBUE097-10; KF671008), EC169-101Pe[M] (WRBUE100-10; KF671007), EC169-102(Pe)F, EC169-103(Pe)M, EC169-104(Pe)F, EC169-105(Pe)F, EC169-106(Pe)F, EC169-107(Pe)F, EC169108Pe[M] (WRBUE104-10; KF671010), EC169-109(Pe)F, EC169-110(Pe)F, EC169-111(Pe)[M] (WRBUE106-10 \& SOIE296-13; KF671011), EC169-112(Pe)F, EC169-113(Pe)M, EC169-114(Pe)F, EC169-115(Pe)[M] (WRBUE108-10; KF671006), EC169-116(Pe)M, EC169-117(Pe)M, EC169-118(Pe)F, EC169-119(Pe)F, EC169-120(Pe)[M] (WRBUE10710; KF671005), EC169-121(Pe)M, EC169-122(Pe)M, EC169-123(Pe)F, EC169-124(Pe)F, EC169-125(Pe)[M] (WRBUE110-10; KF671009), EC169-127(Pe)M, EC169-128(Pe)M, EC169-129(Pe)F, EC169-130(Pe)F, EC169-131(Pe)F, EC169A[F], EC170-103PeM, EC172-003LePeF, EC216[20L], EC216-131PeF, EC216-132PeM, EC216-133PeF, EC216134PeM, EC216-139PeM, EC216-145PeM, EC216-151PeM, EC258-001LePeM, EC260-100PeM; Ch. sp. nr. fajardoi $(\mathrm{n}=12), \mathrm{EC125-104Pe[F]} \mathrm{(WRBUE077-10;} \mathrm{KF671012),} \mathrm{EC153-001LePeF,} \mathrm{EC153-100PeF,} \mathrm{EC170-003LePeF,} \mathrm{EC170-}$ 004LePeF, EC170-100(Pe)F, EC170-101(Pe)F, EC170-102Pe[M] (WRBUE115-10; KF671013), EC257-001LePeM, EC257-002LePeM, EC257-003LePeM, EC257-004LePeF; Ch. sp. undet. (n = 5), EC255[5L].

Culex - Cx. (And.) bamborum (n = 7), EC131-002LePeM, EC131-003LePeF, EC131-004LePeM, EC133-005LePeF, EC254-007LePeMGen05/58, EC254-100PeF, EC254-105PeF; Cx. (And.) browni $(\mathrm{n}=2), \mathrm{EC} 118-004 \mathrm{LePe}[\mathrm{M}]$ (WRBUE091-10; KF671016), EC133-002LePeF; Cx. (And.) sp. nr. conservator ( $\mathrm{n}=38$ ), EC110-001LePeMGen01/14, EC118-001LePeMGen01/28, EC118-005LePeF, EC118-006LePeF, EC118-007LePeM, EC118-009LePeF, EC118-010LePeM, EC118-011LePeM, EC118-014LePe[M] (WRBUE094-10; KF671017), EC118-016LePeF, EC118-017LePeM, EC118-019LePeF, EC118-020LePeM, EC118-021LePeF, EC118-022LePeF, EC118-023LePeF, EC118-026LePeF, EC118-027LePeM, EC118-028LePeF, EC118-029LePeM, EC118-030LePeF, EC118-032LePeF, EC118-033LePeM, EC118-036LePeMGen01/29, EC118-038LePeM, EC118-040LePeF, EC118-100PeF, EC118-101PeF, EC118-102PeF, EC118-103PeF, EC118-104PeM, EC118-105PeM, EC118-106PeF, EC118-108PeM, EC118-109PeM, EC118-113PeF, EC118-115PeM, EC118-132PeF; Cx. (Car.) bonnei (n = 36), EC123-024LePeMGen01/38, EC123-025LePeF, EC136004LePeM, EC136-005LePeM, EC136-006LePeF, EC136-009LePeF, EC136-010LePeF, EC136-011LePeF, EC136012LePeF, EC136-013LePeF, EC136-014LePe[M] (WRBUE119-10; KF671015), EC136-015LePeF, EC136-016LePeM, EC136-017LePeMGen02/26, EC136-018LePeM, EC136-100PeF, EC136-101Pe[M] (WRBUE078-10; KF671014), EC136-102PeF, EC136-103PeF, EC136-104PeM，EC136-106PeF，EC136-110PeF，EC136-111PeF， EC136-112PeF, EC136-113PeF, EC136-114PeM, EC136-115PeM, EC136-116PeM, EC136-117PeM, EC136-118PeM, EC136-119PeM, EC136-120PeM, EC136-121PeF, EC136-122PeF, EC136-123PeF, EC154-004LePeM; Cx. (Car.) iridescens $(\mathrm{n}=4)$, EC270-002LePeF, EC270-003LePeM, EC270-004LePeM, EC270-100PeM; Culex (Car.) secundus (n = 4), EC254002LePeM, EC254-010LePeMGen05/57, EC254-102PeF, EC254-104PeM; Cx. (Car.) urichii (n = 141), EC103-001LePeMGen01/02, EC103-002LePeM, EC103-003LePeM, EC103-004LePeM, EC103-005LePeM, EC103-006LePeM, EC103-007LePeM, EC103-008LePeF, EC103-009LePeF, EC103-010LePeF, EC103-011LePeF, EC103-012LePeF, EC103-013LePeM, EC103-014LePeF, EC103-015LePeF, EC103-016LePeF, EC103-017LePeF, EC103-018LePeF, EC103-019LePeF, EC103-020LePeM, EC103-021LePeM, EC103-022LePeF, EC103-023LePeM, EC103-024LePeF, EC103-025LePeF, EC103-026LePeF, EC103-027LePeM, EC103-028LePeM, EC103-029LePeF, EC103-030LePeM, EC103-031LePeM，EC103-032LePeM，EC103-033LePeF，EC103-100PeM，EC103-101Pe[M] (WRBUE068-10; KF671019), EC103-102PeF, EC103-103PeF, EC103-104PeF, EC103-105Pe[M] (WRBUE085-10; KF671022), EC103106PeF, EC110-100PeF, EC113-002F, EC114-002Pe, EC114-006LePeM, EC115-001LePe[M] (WRBUE087-10; KF671021), EC115-002LePeF, EC115-003LePeMGen01/22, EC115-010LePe[M] (WRBUE102-10; KF671023), EC115-011LePeM, EC115-013LePeF, EC115-014LePeM, EC115-015LePeM, EC115-016LePeM, EC115-017LePeF, EC115-018LePeF, EC115-019LePeM, EC115-020LePeM, EC115-021LePeF, EC115-022LePeF, EC115-023LePeF, EC115-024LePeM, EC115-025LePeF, EC115-026LePeM, EC115-027LePeM, EC115-028LePeF, EC115-029LePeM, EC115-030LePeM, EC115-031LePeF, EC115-032LePeF, EC115-033LePeF, EC115-034LePeF, EC115-035LePeM, EC115-036LePeM, EC115-037LePeF, EC115-038LePeF, EC115-039LePeF, EC115-040LePeM, EC115-041LePeF, EC115-042LePeF, EC115-043LePeM, EC115-044LePeM, EC115-045LePeF, EC115-105PeM, EC115-106PeM, EC115107PeF, EC116-001LePeF, EC116-002LePeF, EC116-004LePeM, EC116-005LePeF, EC116-006LePeM, EC116-007LePeF, EC116-008LePeM, EC116-009LePeF, EC116-010LePeF, EC116-011LePeMGen01/24, EC116-012LePeF, EC116-013LePeM, EC116-014LePeF, EC116-015LePeF, EC116-016LePeF, EC116-017LePeF, EC116-018LePeM, EC116-019LePeM, EC116-100PeMGen01/25, EC116-101PeM, EC116-102PeM, EC116-103PeM, EC116-104PeM, EC116-105PeF, EC120-001LePeF, EC121-001LePeF, EC121-002LePe[M] (WRBUE093-10; KF671020), EC121-009LePeMGen01/33, EC121-010LePeM, EC121-011LePeF, EC121-012LePeF, EC121-013LePeF, EC121-100PeF, EC121108[?](WRBUE069-10; KF671024), EC121-109PeF, EC121-111PeF, EC121-113PeF, EC121-114F, EC121-118PeM, EC122-002LePeF, EC122-003F, EC122-101PeF, EC122-102F, EC123-005LePeM, EC133-001F, EC135-001LePeM, 
EC140-001LePeF, EC140-002LePeF, EC140-003LePeM, EC140-004LePeM, EC140-005LePeM, EC140-006LePeM, EC140-007LePeM, EC140-100PeM, EC140-101PeF, EC140-102PeM; Cx. (Car.) wilsoni (n = 23), EC196-003LePeMGen02/30, EC196-006LePeM, EC205-001LePeM, EC206[3L], EC206-001LePeM, EC206-002LePeM, EC206-003LePeM, EC206-004LePeMGen02/18, EC206-005LePeF, EC206-006LePeM, EC206-007LePeF, EC206008LePeF, EC206-009LePeF, EC206-010LePeF, EC206-011LePeF, EC206-012LePeM, EC206-013LePeF, EC206014LePeM, EC206-015LePeF, EC206-016LePeF, EC206-100PeM; Cx. (Cux.) bonneae (n = 21), EC149[15L], EC149001LePeMGen02/27, EC149-002LePeM, EC149-003LePeM, EC149-004LePeM, EC149-005LePeF, EC149-006LePeF, EC166-005LePeF; Cx. (Cux.) camposi $(\mathrm{n}=3)$, EC130-102PeMGen05/59, EC134-005LePeMGen05/34, EC134-102Pe[M]Gen13/02; Cx. (Cux.) coronator s.l. $(\mathrm{n}=50), \mathrm{EC} 130-001 \mathrm{LePeF}, \mathrm{EC} 130-002 \mathrm{LePeF}$, EC130-003LePeF, EC130-004LePeF, EC130-101PeF, EC134[15L], EC134-001LePeF, EC134-002LePeF, EC134-003LePeF, EC134-004LePeF, EC134-006LePeF, EC134-007LePeF, EC134-008LePeF, EC134-009LePeF, EC134-012LePeF, EC134-013LePeF, EC134-014LePeM, EC134-015LePeM, EC134-016LePeF, EC134-017LePeF, EC134-018LePeF, EC134-019LePeM, EC134-020LePeF, EC134-021LePeF, EC134-100PeF, EC134-101PeF, EC134-103PeF, EC134-104PeF, EC134-105PeM, EC134-106PeM, EC134-107PeM, EC134-108PeF, EC134-109PeF, EC134-110PeF, EC134-111PeM, EC137-100PeM; Cx. (Cux.) mollis $(\mathrm{n}=181)$, EC113-001LePeF, EC113-100PeMGen01/20, EC113-101PeF, EC113-102PeM, EC115-108PeF, EC116-003LePeMGen01/23, EC118-002LePeMGen01/30, EC118-003LePeF, EC118-008LePeF, EC118-012LePeM, EC118-013LePeF, EC118-015LePeF, EC118-018LePeF, EC118-024LePeM, EC118-031LePeM, EC118-034LePeF, EC118-035LePeF, EC118-107PeM, EC118-110PeF, EC118-111PeM, EC118-112PeF, EC118-114PeM, EC118-116PeF, EC118-117PeM, EC118-118PeM, EC118-119PeF, EC118-120PeF, EC118-121aPeF, EC118-121bPeF, EC118-122PeM, EC118-123PeM, EC118-124PeM, EC118-125PeM, EC118-126PeM, EC118-127PeM, EC118-128PeM, EC118-129PeM, EC118-130PeF, EC118-131PeM, EC120-101PeF, EC120-103PeF, EC121-003LePeM, EC121-004LePeM, EC121-005LePeF, EC121-006LePeM, EC121-007LePeF, EC121-008LePeM, EC121-101PeF, EC121-102PeF, EC121-103PeF, EC121-104PeF, EC121-105PeF, EC121-112PeM, EC121-115M, EC121-116PeF, EC121117PeF, EC122-001LePeF, EC123-001LePeMGen01/37, EC123-002LePeF, EC123-003F, EC123-004LePeF, EC123007LePeF, EC123-008LePeM, EC123-009LePeF, EC123-010LePeF, EC123-011LePeF, EC123-012LePeF, EC123013LePeMGen01/36, EC123-014LePeF, EC123-015LePeM, EC123-016LePeM, EC123-017LePeM, EC123-018LePeMGen01/35, EC123-019LePeM, EC123-020LePeF, EC123-021LePeF, EC123-022LePeF, EC123023LePeF, EC123-100PeF, EC123-101PeF, EC123-102PeM, EC123-103PeF, EC123-104PeF, EC123-105PeM, EC123106PeM, EC123-107PeM, EC123-108PeM, EC123-109PeM, EC123-110PeM, EC123-111PeM, EC123-112PeF, EC123113PeM, EC123-114PeM, EC123-115PeM，EC136-002LePeF，EC136-003LePeMGen02/25，EC136-007LePeF, EC136-008LePeF, EC141-001LePeM, EC141-002LePeMGen05/35, EC141-003LePeM, EC141-004LePeM, EC141005LePeF, EC141-006LePeF, EC141-100PeM, EC141-101PeM, EC143-001LePeMGen02/62, EC150[10L], EC150002LePeF, EC150-003LePeF, EC150-004LePeM, EC150-005LePeF, EC150-006LePeF, EC150-007LePeF, EC150008LePeF, EC150-009LePeF, EC150-100PeM, EC150-101PeM, EC150-102PeMGen02/21, EC150-103PeM, EC150-104PeM, EC150-105PeM, EC150-106PeM, EC150-107PeM, EC150-108PeM, EC150-109PeM, EC150-110PeM, EC150-111PeM, EC150-112PeM, EC150-113PeM, EC150-114PeM, EC150-115PeM, EC150-116PeF, EC150-117PeM, EC150-118PeF, EC150-119PeM, EC150-120PeM, EC150-121PeM, EC150-122PeM, EC150-123PeM, EC150124PeM, EC150-125PeM, EC150-126PeM, EC150-127PeM, EC150-128PeM, EC150-129PeM, EC150-130PeM, EC150-131PeM,EC150-132PeM,EC154-001LePeM,EC154-002LePeF,EC154-003LePeM,EC154-100PeMGen05/37, EC157-100PeMGen05/38, EC157-101PeM, EC157-102PeM, EC157-103PeM, EC157-104PeF, EC157-105PeF, EC157106PeF, EC157-107PeF, EC162-100PeF, EC183-001LePeMGen05/42, EC183-002LePeF, EC183-003LePeF, EC183004LePeF, EC183-005LePeF, EC183-100LePeM, EC183-101LePeM, EC183-102LePeM, EC183-103LePeM, EC121110MGen01/34; Cx. (Cux.) usquatus $(\mathrm{n}=2$ ), EC134-010LePe[M]Gen13/01, EC134-011LePeMGen05/61; Cx. (Cux.) sp. undet. $(\mathrm{n}=17)$, EC139(3F), EC259(9F), EC219(2F), EC219(3F); Cx. (Mcx.) chryselatus $(\mathrm{n}=22)$, EC105-001LePeMGen01/03, EC105-003LePeF, EC105-004LePeF, EC105-005LePeM, EC105-100PeMGen01/04, EC105-101PeM, EC105-102PeM, EC166-001LePeF, EC207-003LePeF, EC207-101PeM, EC207-102PeM，EC207-103PeM, EC208-003PeMGen02/31, EC208-004PeF, EC208-005PeF, EC208-006PeMGen05/47, EC208-007PeF, EC208-008PeF, EC208-009PeM, EC208-010PeM, EC208-011PeF, EC208-012PeF; Cx. (Mcx.) pleuristriatus (n = 11), EC164001LePeF，EC164-002(LePe)F，EC164-003(LePe)F，EC164-004(LePe)F，EC164-005(LePe)F，EC164-100(Pe)F, EC164-101PeM, EC164-102(Pe)MGen02/20, EC196-001LePeM, EC196-002LePeF, EC196-004LePeM, EC196-005LePeF, EC196-007LePeMGen02/29, EC196-008LePeF, EC196-009LePe; $C x$. (Mcx.) sp. undet. (n = 3), EC256-100PeF, EC268-102PeF, EC207-001LePeF; Cx. (Mcx.) stonei ( $\mathrm{n}=1$ ), EC166-100PeM; Cx. (Mel.) eastor (n= 4), EC112016LePeF, EC112-102PeM, EC112-108PeMGen01/19, EC112-109PeF; Cx. (Mel.) elevator $(\mathrm{n}=45)$, EC100-001LePeMGen01/01, EC100-002LePeM, EC100-003LePeM, EC100-004LePeF, EC100-100PeM, EC100101PeMGen01/43, EC125-013LePeF, EC125-015LePeF, EC125-016LePeF, EC125-017LePeF, EC125-018LePeF, EC125-100PeM, EC125-102PeMGen01/40, EC125-108PeF, EC125-109PeF, EC125-111PeM, EC125-112PeF, EC125113PeMGen01/41, EC125-114PeM, EC125-115PeM, EC125-116PeF, EC125-117PeF, EC125-118PeF, EC125-119PeM, EC125-120PeF, EC125-121PeF, EC125-122PeM, EC125-123PeF, EC125-125PeMGen01/42, EC125-127PeF, EC125129PeF, EC125-130PeF, EC125-131PeF, EC128-105PeM, EC128-107PeF, EC128-108PeF, EC128-110PeM, EC128111PeM, EC128-112PeMGen02/24, EC128-113PeM, EC128-114PeM, EC145-100PeMGen02/64, EC145-101PeM, 
EC152-101PeMGen05/36, EC198-001LePeMGen05/44; Cx. (Mel.) evansae (n = 8), EC146-004LePeMGen02/65, EC148-108PeF, EC148-109PeMGen02/67, EC148-110PeMGen02/22, EC148-111PeM, EC148-112PeM, EC148-113PeM, EC148-114PeM; Cx. (Mel.) iolambdis (n = 5), EC125-008LePeMGen01/39, EC125-012LePeF, EC125-124PeM, EC125-126PeM, EC125-128PeM; Cx. (Mel.) pilosus (n = 18), EC130-100PeMGen05/60, EC199-001LePeM, EC199003LePeF, EC199-004LePeF, EC199-005LePeM, EC199-100PeM, EC199-101PeF, EC199-102PeM, EC199-103PeF, EC199-104PeF, EC199-105PeF, EC199-106PeM, EC199-107PeM, EC199-108PeM, EC199-109PeMGen02/19, EC199110PeM, EC199-111PeM, EC259MGen12/13; Cx. (Mel.) serratimarge ( $\mathrm{n}=19)$, EC112-001LePeM, EC112-002LePeF, EC112-003LePeF, EC112-004LePeF, EC112-005LePeMGen01/15, EC112-006LePeF, EC112-007LePe[M] (WRBUE088-10; KF671018), EC112-009LePeF, EC112-011LePeM, EC112-012LePeF, EC112-013LePeF, EC112-014LePeMGen01/16, EC112-017LePeM, EC112-018LePeF, EC112-100PeMGen01/18, EC112-101PeM, EC112-103PeM, EC112-106PeF, EC112-107PeM; Cx. (Mel.) symbletos (n = 2), EC112-015LePeMGen01/17, EC112-111PeM; Cx. (Mel.) theobaldi $(\mathrm{n}=9$ ), EC199-002LePeMGen05/45, EC199-112PeF, EC216-107PeF, EC255-100PeM, EC255-101PeM, EC255-102PeM, EC255-103PeM, EC259MGen12/14, EC259MGen12/15; Cx. (Mel.) vomerifer (n = 1), EC259(1F); Cx. (Mel.) sp. undet. $(\mathrm{n}=75)$, EC112-110PeM, EC148-115PeM, EC256-101PeF, EC256-103PeF, EC259(1F), EC259(25F), EC259(38M), EC269-011LePeM, EC269-012LePeM, EC148-006LePeF, EC148-007LePeF, EC269013LePeM, EC269-104PeF, EC269-105PeF.

Haemagogus - Hg. (Hag.) janthinomys ( $\mathrm{n}=1$ ), EC111-001LePeF; Hg. (Hag.) sp. undet. (n = 1), EC259(1F).

Limatus - Li. durhamii (n = 61), EC120-100PeMGen01/31, EC136-109PeF, EC155-001LePeF, EC155-002LePeF, EC155-003LePeF, EC155-004LePeF, EC155-005LePeF, EC155-006LePeM, EC155-007LePeM, EC155-008LePeM, EC155-009LePeM, EC155-010LePeF, EC155-011LePeM, EC155-012LePeF, EC155-013LePeM, EC155-014LePeM, EC155-015LePeF, EC155-016LePeM, EC155-017LePeM, EC155-018LePeM, EC155-019LePeF, EC155-020LePeF, EC155-021LePeF, EC155-022LePeF, EC155-023LePeM, EC155-024LePeM, EC155-025LePeM, EC155-026LePeM, EC155-027LePeM, EC155-028LePeM, EC155-029LePeM, EC155-030LePeF, EC155-031LePeF, EC155-100PeF, EC155-101PeM, EC155-102PeF, EC155-103PeF, EC155-104PeF, EC155-105PeM, EC155-106PeM, EC155-107PeM, EC155-108PeF, EC155-109PeF, EC155-110PeF, EC155-111PeM, EC155-112PeM, EC155-113PeM, EC155-114PeF, EC155-115PeM, EC155-116PeF, EC188[3L], EC188-001LePeF, EC188-002LePeF, EC188-003LePeF, EC188-100PeF, EC188-101PeM, EC188-102PeF, EC188-103Pe; Li. flavisetosus ( $\mathrm{n}=29$ ), EC115-004LePeM, EC115-005LePeM, EC115-006LePeM, EC115-007LePeM, EC115-008LePeM, EC115-009LePeF, EC115-012LePe[M](WRBUE103-10; KF671027), EC115-100PeM, EC115-101PeMGen01/21, EC115-102PeF, EC115-103PeF, EC115-104PeF, EC115-109PeF, EC115-110PeF, EC115-111Pe[M], EC115-112PeM, EC115-113PeM, EC115-114PeF, EC118-025LePeF, EC120102PeMGen01/32, EC136-105PeF, EC136-107PeF, EC136-108PeM, EC171-001LePeF, EC175-001LePeF, EC175-100PeF, EC201-001LePeF, EC201-100PeF, EC201-101PeF; Li. sp. undet. (n=1), EC136-001LePe[M].

Lutzia - Lt. (Lut.) allostigma ( $\mathrm{n}=14)$, EC114-001LePe[M] (WRBUE076-10; KF671030), EC114-003LePeF, EC114-004LePeF, EC114-005LePeF, EC114-007LePeM, EC114-100PeF, EC114-101PeF, EC121-106PeF, EC121107PeF, EC122-100Pe[M] (WRBUE071-10; KF671029), EC124[F] (WRBUE065-10; KF671028), EC217-100PeM, EC217-101PeM, EC217-102PeF.

Ochlerotatus - Oc. (Chs.) fulvus $(\mathrm{n}=27), \mathrm{EC} 259(1 \mathrm{~F}), \mathrm{EC139}(26 \mathrm{~F}) ;$ Oc. $($ Pcx.) serratus $(\mathrm{n}=5), \mathrm{EC148}-101 \mathrm{PeF}$, EC148-102PeF, EC148-103PeF, EC148-105PeF, EC148-106PeF; Oc. (Pro.) argyrothorax (n = 2), EC142-001LePeF, EC142-002LePeF; Oc. sp. undet. (n=1), EC259(1F).

Onirion - On. imparis $(\mathrm{n}=5)$, EC202-001LePeF, EC202-002F, EC202-003LePeM, EC202-004LePeF, EC254005LePeMGen05/32.

Orthopodomyia - Or. fascipes ( $\mathrm{n}=3$ ), EC176-100PeF, EC176-101PeM, EC197-002LePeF.

Psorophora - Ps. (Gra.) cingulata $(\mathrm{n}=1)$, EC139(1F); Ps. (Jan.) albipes $(\mathrm{n}=1), \mathrm{EC} 259(1 \mathrm{~F}) ;$ Ps. (Jan.) albigenu $(\mathrm{n}$ =4), EC139(3F), EC148-107PeF; Ps. (Jan.) lanei (n = 1), EC139(1F); Ps. (Jan.) sp. undet. (n=3), EC219(3F).

Runchomyia - Ru. (Cte.) magna (n=1), EC130-005LePeF.

Sabethes - Sa. (Pey.) sp. nr. luxodens $(\mathrm{n}=4)$, EC132-003LePeF, EC132-004LePeM, EC132-005LePeF, EC132007LePeMGen02/59; Sa. (Sab.) sp. undet. (n=1), EC219(1F).

Toxorhynchites - Tx. (Lyn.) bambusicola $(\mathrm{n}=3)$, EC197-001LePeMGen05/63, EC203-001LePeF, EC254-011LePeF; Tx. (Lyn.) haemorrhoidalis $(\mathrm{n}=9$ ), EC267-001LePe[?], EC267-002LePe[?], EC267-003LePeM, EC267-004M, EC267-005F, EC267-006LePeM, EC267-007M, EC267-008LePeF, EC270-001LePeM; Tx. (Lyn.) sp. undet. (n = 2), 


\section{EC212-001LePe[M](WRBUE090-10; KJ671031), EC256-102PeF.}

Trichoprosopon - Tr. digitatum $(\mathrm{n}=279)$, EC117-001LePeMGen01/26, EC117-002LePeF, EC117-003LePeF, EC117-004LePeM, EC117-005LePeF, EC117-006LePeF, EC117-007LePeF, EC117-008LePeF, EC117-009LePeF, EC117-010LePeM，EC117-011LePeM，EC117-012LePeF，EC117-013LePeF，EC117-014LePeF，EC117-015LePeF, EC117-016LePeM, EC117-017LePeM, EC117-018LePeF, EC117-019LePeM, EC117-020LePeF, EC117-021LePeF, EC117-100Pe[M] (WRBUE113-10; KF671032), EC118-037LePeMGen01/27, EC118-039LePeM, EC118-041LePe, EC118-042LePeM, EC127(A)[F] (WRBUE080-10; KF671033), EC139(1F), EC157-001LePeM, EC157-002LePeM, EC157-003LePeM, EC157-004LePeF, EC157-108PeM, EC157-109PeF, EC157-110PeF, EC165-001LePeM, EC165002LePeF，EC167-001LePeM，EC167-002LePeM，EC165-003(LePe)F，EC165-004(LePe)F，EC165-005(LePe)F, EC165-006(LePe)F, EC165-100(Pe)M, EC165-101(Pe)M, EC165-103(Pe)M，EC165-104(Pe)M, EC165-105(Pe)M, EC165-106(Pe)M, EC165-107(Pe)F, EC165-108(Pe)F, EC165-109(Pe)F, EC165-110(Pe)F, EC165-111(Pe)F, EC165112(Pe)F, EC167[15L], EC167-003(LePe)M, EC167-004(LePe)F, EC167-005(LePe)M, EC167-006(LePe)F, EC167007(LePe)F, EC167-008(LePe)M, EC167-009(LePe)M, EC167-010(LePe)F, EC167-011(LePe)F, EC167-012(LePe)F, EC167-013(LePe)F, EC167-014(LePe)F, EC167-015(LePe)F, EC167-016(LePe)F, EC167-017(LePe)F, EC167-018(LePe) F, EC167-100(Pe)M, EC167-101(Pe)M, EC167-102(Pe)M, EC167-103(Pe)M, EC167-104(Pe)M, EC174-001LePeM, EC174-002LePeM, EC174-003(LePe)M, EC174-004(LePe)F, EC174-005(LePe)F, EC174-100(Pe)M, EC177-001LePeM, EC177-002LePeM, EC177-003LePeF, EC177-004LePeF, EC177-005LePeM，EC177-006LePeF, EC177-100PeM, EC177-101PeF, EC178[5L], EC178[7L], EC178-001LePeM, EC178-002LePeM, EC178-003LePeM, EC178100PeM, EC178-101PeM, EC178-102PeM, EC178-103PeM, EC178-104PeM, EC179-001LePeF, EC179-002LePeF, EC179-100M, EC179-101PeF, EC179-102PeM, EC179-103PeF, EC179-104PeM, EC179-105PeM, EC180-001LePeM, EC180-002LePeM, EC180-003LePeF, EC180-004LePeF, EC180-005LePeF, EC180-006LePeM, EC180-007LePeM, EC180-008LePeF, EC180-009LePeF, EC180-010LePeF, EC180-011LePeF, EC180-012LePeF, EC180-013LePeF, EC180-100PeM, EC180-101PeM, EC180-102PeM, EC180-103PeF, EC180-104PeF, EC180-105PeM, EC181[10LP], EC181-001LePeF, EC181-002LePeM, EC181-003LePeM, EC181-004LePeF, EC181-100PeM, EC181-101PeF, EC181102PeM, EC181-103PeM, EC184-001LePeM, EC184-002LePeF, EC184-003LePeM, EC184-004LePeF, EC184-005LePeM, EC184-006LePeM, EC184-007LePeF, EC184-008LePeF, EC184-009LePeF, EC184-010LePeF, EC184-100PeM, EC184-101PeF, EC184-102PeF, EC184-103PeMGen05/41, EC184-104M, EC184-105PeM, EC186-001LePeF, EC186-002LePeF, EC186-003LePeF, EC186-004LePeF, EC186-005LePeF, EC186-006LePeF, EC186-007LePeM, EC186-100PeF, EC186-101PeM, EC186-102PeM, EC186-103PeM, EC186-104PeM, EC186-105PeM, EC186-106PeM, EC186-107PeM, EC186-108PeM, EC186-109PeF, EC186-110PeF, EC186-111PeM, EC186-112PeM, EC186-113PeM, EC186-114PeF, EC186-115PeF, EC187-001LePeM, EC187-002LePeM, EC187-003LePeF, EC187-004LePeM, EC187005LePeM, EC187-006LePeF, EC187-007LePeF, EC187-008LePeF, EC187-009LePeF, EC187-010LePeF, EC187-011LePeF, EC187-012LePeF, EC187-013LePeF, EC187-014LePeF, EC187-015LePeF, EC187-016LePeF, EC187-017LePeF, EC187-018LePeF, EC187-019LePeF, EC187-020LePeF, EC187-021LePeM, EC187-022LePeF, EC187-023LePeF, EC187-100PeM, EC187-101PeM, EC187-102PeM, EC187-103PeM, EC187-104PeM, EC187-105PeM, EC187-106PeM, EC187-107PeM, EC187-108PeM, EC187-109PeM, EC187-110PeM, EC187-111PeM, EC187-112PeM, EC189-002LePeM, EC189-003LePeF, EC208-001PeM, EC208-002PeF, EC209-100PeF, EC209-101PeF, EC210-001LePeF, EC213001LePeM，EC213-002LePeM，EC213-003LePeM，EC214-001LePeM，EC214-002LePeM，EC214-003LePeM， EC214-004LePeM, EC214-005LePeF, EC214-006LePeF, EC214-007LePeF, EC214-008LePeF, EC214-009LePeM, EC214-010LePeF, EC214-011LePeM, EC214-100PeM, EC214-101PeF, EC214-102PeF, EC214-103PeM, EC217-103PeM, EC219(4F), EC259(2F), EC264-002(LePe)F, EC264-003(LePe)F; Tr. sp. nr. lampropus (n = 2), EC194-003LePeMGen05/43, EC194-004LePeF.

Uranotaenia - Ur. (Ura.) calosomata (n = 2), EC112-104PeM, EC112-105Pe[M] (WRBUE098-10; KF671034).

Wyeomyia - Wy. (Dec.) pseudopecten $(\mathrm{n}=19)$, EC108-001LePeMGen01/11, EC144-001LePeM, EC144-002LePeF, EC144-003LePeF, EC144-004LePeM, EC144-005LePeF, EC144-006LePeF, EC144-007LePeF, EC144-100PeM, EC144-101PeF, EC144-102PeM, EC144-103PeMGen02/63, EC144-104PeM, EC144-105PeF, EC144-106PeM, EC144-107PeM, EC144-108PeF, EC144-109PeF, EC195-100PeMGenCP; Wy. (Dec.) ulocoma (n = 462), EC106[20L], EC106[50L], EC106-001LePeMGen01/05, EC106-002LePeM, EC106-003LePeM, EC106-004LePeF, EC106-005LePeM, EC106-006LePeF, EC106-007LePeF, EC106-008LePeF, EC106-009LePeM, EC106-010LePeF, EC106-011LePe[F] (WRBUE066-10; KF671040), EC106-012LePeF, EC106-013LePeF, EC106-014LePeF, EC106-015LePeF, EC106-016LePeF, EC106-017LePeF, EC106-018LePeF, EC106-019LePeM, EC106-020LePeM, EC106-021LePe[M] (WRBUE075-10; KF671039), EC106-022LePeM, EC106-023LePeF, EC106-024LePeF, EC106-025LePeF, EC106026LePeF, EC106-027LePeF, EC106-028LePeM, EC106-029LePeF, EC106-030LePeF, EC106-031LePeF, EC106032LePeF, EC106-033LePeF, EC106-034LePeF, EC106-035LePeF, EC106-036LePeF, EC106-037LePeF, EC106100PeF, EC106-101PeMGen01/08, EC106-102PeF, EC106-103PeF, EC106-104PeF, EC106-105PeMGen01/06, EC106-106PeF, EC106-107PeF, EC106-108PeM, EC106-109PeM, EC106-110PeF, EC106-111Pe[M] (WRBUE072-10; KF671038), EC106-112Pe[M] (SOIE294-13; KF671042), EC106-113PeM, EC106-114PeF, EC106-115PeF, EC106-116- 
PeM, EC106-117PeF, EC106-118PeM, EC106-119PeM, EC106-120PeM, EC106-121Pe[M] (SOIE293-13; KF671043), EC106-122PeM, EC106-123PeMGen01/07, EC106-124PeM, EC106-125PeM, EC106-126PeM, EC107-001LePeM, EC107-003LePeMGen01/09, EC107-004LePeF, EC107-005LePeM, EC107-006LePeM, EC107-007LePeF, EC107008LePeM, EC107-010LePeF, EC107-011LePeF, EC107-012LePeMGenCP, EC107-013LePeF, EC107-014LePeM, EC107-015LePeF, EC107-017LePeF, EC107-018LePeM, EC107-020LePeM, EC107-021LePeM, EC107-023LePeM, EC107-025LePeF, EC107-026LePeM, EC107-027LePeF, EC107-028LePeM, EC107-100PeF, EC107-102PeM, EC107-103PeM, EC107-104PeF, EC107-105PeM, EC107-106PeF, EC107-108PeF, EC107-109PeM, EC107-110PeF, EC107-111PeF, EC107-112PeM, EC107-113PeM, EC107-114PeM, EC107-115PeM, EC107-116Pe[M] (WRBUE07310; KF671044), EC107-118PeM, EC107-119PeM, EC107-120PeM, EC107-121PeM, EC107-122PeM, EC107-123PeM, EC107-124PeM, EC107-125PeF, EC107-126PeM, EC107-127PeM, EC107-128PeM, EC158-002LePeF, EC158-003LePeF, EC158-004LePeM, EC158-005LePeF, EC158-006LePeM, EC158-007LePeM, EC158-010LePeF, EC158-011LePeF, EC158-100PeF, EC158-101Pe[M] (WRBUE096-10; KF671037), EC158-102PeM, EC158-103Pe, EC158-104PeM, EC158-105PeM, EC159-001LePeF, EC159-002LePeF, EC159-003LePeF, EC159-004LePeM, EC159-005LePeF, EC159-006LePeF, EC159-007LePeM, EC159-008LePeF, EC159-010LePeM, EC159-011LePeM, EC159-013LePeF, EC159-016LePeF, EC159-017LePeF, EC159-018LePeF, EC159-019LePeF, EC159-019LePeF, EC159-020LePeF, EC159-021LePeF, EC159-022LePeF, EC159-023LePeF, EC159-100PeM, EC159-101PeM, EC159-102PeM, EC159103PeM, EC159-104PeM, EC159-105PeF, EC159-106PeF, EC159-107PeM, EC159-108PeM, EC159-109PeM, EC159110PeM, EC159-111PeM, EC160[15L], EC160[15L], EC160-001LePe, EC160-002LePeMGen05/39, EC160-003LePeF, EC160-004LePeM, EC160-005LePeM, EC160-006LePeM, EC160-007LePeF, EC160-008LePeF, EC160-100PeF, EC160-102Pe[M] (WRBUE095-10; KF671041), EC160-103PeF, EC160-104PeF, EC160-106PeF, EC160-107PeM, EC160-108PeF, EC160-109PeM, EC160-110PeM, EC160-111PeF, EC160-112PeM, EC160-113PeF, EC160-114PeM, EC160-115PeM, EC160-116PeF, EC160-117PeF, EC160-118PeM, EC160-119PeF, EC160-120PeF, EC160-121PeF, EC160-122PeM, EC160-123PeM, EC160-124PeM, EC160-125PeM, EC160-126PeM, EC160-127PeF, EC160-128PeF, EC160-129PeM, EC160-130PeM, EC160-131PeF, EC160-132PeM, EC160-133PeF, EC160-134PeF, EC161-001(LePe)M, EC161-002(LePe)F, EC161-003(LePe)F, EC161-004(LePe)F, EC161-005(LePe)F, EC161-102(Pe)M, EC173001LePeM, EC173-100(Pe)F, EC173-101PeM, EC215-001LePeF, EC215-002LePeMGen05/48, EC215-003LePeF, EC215-100PeM, EC218-001LePe, EC218-002LePeF, EC218-003F, EC218-004LePeF, EC218-005LePeF, EC218-100PeF, EC218-102PeM, EC218-104PeF, EC218-106PeM, EC218-107PeF, EC218-108PeF, EC218-109PeF, EC218-110PeF, EC218-112PeF, EC218-113PeF, EC264(64M), EC264(68F), EC264-104PeMGenCP, EC264-105PeMGenCP, EC264MGen12/11, EC264MGen12/12; Wy. (Dec.) sp. CP2103 ( $\mathrm{n}=1), \mathrm{EC193-012;} \mathrm{Wy.} \mathrm{(Dec.)} \mathrm{sp.} \mathrm{undet.} \mathrm{(n} \mathrm{=} \mathrm{77),}$ EC158-001LePeF, EC158-008LePeM, EC158-009LePeF, EC158-106PeM, EC159-009LePeM, EC159-012LePeM, EC159-014LePeM, EC159-015LePeF, EC160-101PeM, EC160-105PeF, EC161-100PeM, EC161-101(Pe)MGen05/40, EC189-001LePeM, EC189-100PeMGen05/62, EC189-101PeF, EC189-102PeF, EC189-103PeM，EC189-104PeM, EC189-105PeF, EC189-106PeM, EC193[20L], EC193-001LePeF, EC193-002LePeM, EC193-003LePeF, EC193-004LePeF, EC193-005LePeF, EC193-006LePeF, EC193-007LePeF, EC193-008LePeF, EC193-009LePeF, EC193-010LePeF, EC193-011LePeF, EC193-012LePe, EC193-013LePeF, EC193-014LePeF, EC193-015LePeF, EC193-016LePeF, EC193-100PeM, EC193-101PeF, EC193-102PeF, EC193-103PeF, EC193-104PeM, EC193-105PeF, EC195-101PeF, EC218-101PeF, EC218-103PeF, EC218-105PeM, EC218-111Pe, EC107-002LePeF, EC107-009LePeF, EC107-016LePeF, EC107-019LePeF, EC107-022LePeM, EC107-024LePeM, EC107-101PeM, EC107-107PeF, EC107-117PeM, EC108-100LePeM; Wy. (Dod.) aphobema $(\mathrm{n}=35)$, EC108-002LePeMGen01/12, EC108-003LePeF, EC108-004LePeF, EC108-005LePeF, EC108-006LePeF, EC108-007LePeF, EC108-008LePeF, EC108-009LePeF, EC108-010LePeM, EC108-011LePeM, EC108-012LePeF, EC108-013LePeF, EC108-014LePeMGen01/13, EC108-101PeF, EC108-102PeM, EC108-104PeM, EC108-105PeF, EC135-004LePeF, EC138-001LePeM, EC138-002LePeF, EC138-003LePeF, EC138004LePeF, EC138-005LePeM, EC138-100PeF, EC147-001LePeM, EC147-007LePeF, EC147-008LePeM, EC147009LePeF, EC147-011LePeM, EC147-100Pe[M] (WRBUE092-10; KF671035), EC156-001LePeM, EC161-006LePeF, EC268-001LePeM, EC268-100PeM, EC268-101PeM; Wy. (Dod.) sp. nr. aphobema (n=1), EC156-100Pe[M] (WRBUE099-10; KF671036); Wy. (Hys.) autocratica $(\mathrm{n}=3$ ), EC105-002PeF, EC105-006PeF, EC105-103PeMGenCP; Wy. (Hys.) sp. nr. lamellata $(\mathrm{n}=1)$, EC108-103PeMGen01/10; Wy. (Hys.) sp. undet. $(\mathrm{n}=2)$, EC207-004LePeMGen05/46, EC207-100PeF; Wy. (Mia.) codiocampa (n = 11), EC132-001LePeF, EC132-002LePeM, EC132-006LePeMGen05/28, EC132-008LePeMGen02/60, EC132-009LePeF, EC132-011LePeF, EC132-015LePeF, EC132-100PeF, EC132-101PeF, EC204-002LePeM, EC204-003LePeF; Wy. (Mia.) oblita (n = 3), EC133-003LePeMGen05/30, EC133-004LePeM, EC204-001LePeM; Wy. (Mia.) sp. nr. codiocampa $(\mathrm{n}=1)$, EC132-019LePeMGenCP; Wy. (Mia.) sp. undet. $(\mathrm{n}=11)$, EC132-010LePeF, EC132-012F, EC132-013LePeF, EC132-014MGen05/29, EC132-016LePeF, EC132-017F, EC132018MGen02/61, EC132-020LePeF, EC132-021LePeF, EC132-022LePeF; Wy. (Wyo.) sp. nr. albosquamata $(\mathrm{n}=4)$, EC135-003LePeM, EC147-003LePeMGenCP, EC147-004LePeM, EC147-006LePeF; Wy. (Wyo.) sp. nr. medioalbipes $(\mathrm{n}=1)$, EC104-001LePeF; Wy. (Wyo.) sp. undet. $(\mathrm{n}=6)$, EC135-002LePeF, EC147-002LePeMGen02/66, EC147-005LePeF, EC147-010LePeF, EC147-101PeF, EC147-102PeF. 